\section{Visor Osteotomy of the Anterior Mandible}

\author{
Albino Triaca, DMD, DDS, ${ }^{*}$ Daniel Brusco, DMD, DDS, \\ Roger Minoretti, DMD, DDS, ${ }^{\dagger}$ and \\ Nikola Saulacic, DDS, $P h D^{\ddagger}$
}

\begin{abstract}
Current techniques for three-dimensional correction of the chin in patients with mandibular retrusion may increase mentolabial fold depth, but have limited effect on the lips. The authors present a single surgical technique to support the mentolabial fold and improve labial competence. The visor osteotomy is performed from canine to canine. The bone fragment pedicled to the lingual periosteum is coronally mobilized and fixed in the new position. Preserved vascularization is supposed to minimize the amount of bone resorbed. Visor osteotomy of the anterior mandible may improve the existing treatments for micrognathia by creating an aesthetic mentolabial fold and a competent lip seal.
\end{abstract}

Key Words: Bone graft, mandible, orthognathic surgery

$\mathrm{F}$ acial aesthetics are among the principal factors in decisions about surgical treatment. Patients with mandibular retrusion or microgenia may benefit from genioplasty, which corrects threedimensional chin position and makes the facial profile less convex. ${ }^{1}$ Combining genioplasty with sagittal split advancement osteotomy (SSAO) can improve the aesthetic result. ${ }^{2-5}$ Nevertheless, the remodeling pattern in the area of the osteotomy makes the softtissue profile unpredictable. In the postoperative healing period, the scar contraction may result with thin soft tissues. ${ }^{2}$ Advancing the chin too far can create a marked mentolabial fold and increase softtissue tension.

Various surgical techniques have been suggested to avoid chin ptosis, or "witch-chin." 6 Autogenous bone grafting is often used to avoid an excessive mentolabial fold. ${ }^{7}$ The lateral wings of the genial segment, however, are prone to resorbtion. Surgeons can improve the facial soft-tissue contouring by using fat. ${ }^{8}$ Alloplastic materials were considered preferable for patients who must not activate the mentalis muscle to attain a lip seal. ${ }^{9}$ An outer cortex can be split away from the mandible to achieve the natural position of the mentum and the lower lip, but the risk of infection might be higher because the advancement leaves dead space. ${ }^{10}$ Hence, we introduce the principle of visor to support the mentolabial fold and improve labial incompetence.

$\overline{\text { From the } * \text { Center for Maxillofacial Surgery, Pyramide Clinic; } \dagger \text { Dental }}$ Clinic Am Opernhaus, Zurich; and $\ddagger$ Department of Cranio-Maxillofacial Surgery, University Hospital, Bern, Switzerland.

Received October 3, 2014.

Accepted for publication May 2, 2015.

Address correspondence and reprints requests to Albino Triaca, DMD,

DDS, Center for Maxillofacial Surgery, Pyramide Clinic, Bellerivestrasse 34, CH-8034 Zurich, Switzerland;

E-mail: albino.triaca@swissonline.ch

The authors report no conflicts of interest.

Copyright (1) 2015 by Mutaz B. Habal, MD

ISSN: $1049-2275$

DOI: $10.1097 /$ SCS.0000000000001952

\section{MATERIAL AND METHODS}

\section{Clinical Report}

An 18-year-old girl was referred for treatment of micrognathia inferior congenita. Once orthodontic presurgical alignment was done, cone beam computed tomography (eXam-Vision 3D, Imaging Sciences International, KaVo Dental GmbH, Biberach, Germany) was used to determine the quantity of jaw bone and morphology (Fig. 1A-B). The occlusal plane was corrected by bilateral sagittal split rotation osteotomies. Simultaneously, wing osteotomy was performed to vertically enlarge the mandibular border plane (Fig. 1C-D). ${ }^{11}$ Upper wisdom teeth were also extracted. Two years later, the patient was scheduled for visor osteotomy to increase support of the mentolabial fold. The patient signed a written consent form.

Surgery was performed under local anesthesia. Mucosa was incised in the vestibulum from premolars to premolars, 0.5 to $1.0 \mathrm{~cm}$ from the border to the mucogingival junction. After the labial ramus of the mental nerve was identified, the incision was made, and the full thickness mucoperiosteal flap was carefully elevated to avoid "drop-chin" (Fig. 2A). The osteotomy cut was performed from canine to canine with a Mayfair Bur (EO 540, Maillefer Instruments, Ballaigues, Switzerland), approximately $1 \mathrm{~cm}$ anterior to the mental foramen (Fig. 2B). The osteotomized bone fragment pedicled to the lingual periosteum was mobilized (Fig. 2C) and fixed in the correct position with a screw (Fig. 2D). The wound was closed with a nonresorbable suture, and the mentalis muscle readapted with an additional suture. Figure $1 \mathrm{E}$ to $\mathrm{H}$ show a radiographic view of the chin region immediately after visor osteotomy, and 2 years later. The facial appearance of the patient significantly improved (Fig. 3).

\section{DISCUSSION}

Current concept of visor osteotomy aimed to improve on conventional techniques for microgenia. Härle ${ }^{12}$ introduced a method of osteotomy of the alveolar ridge that moves like a visor. Two bone segments were fixed with wires, which increased the absolute height of the mandibular alveolar ridge. Peterson ${ }^{13}$ modified visor osteotomy by vertical, sagittal splitting of the mandibular body. The lingual segment was elevated along its extent to provide a concurrent vestibuloplasty. Visor osteotomy of the anterior mandible

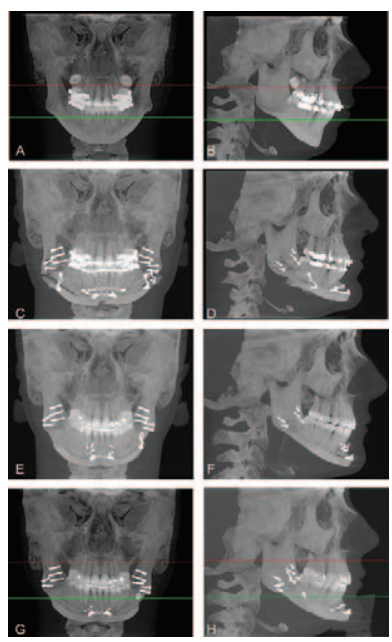

FIGURE 1. A-B, Preoperative anteroposterior and lateral radiographic view of the patient. C-D, Postoperative radiographic view after bilateral sagittal split osteotomy and wing osteotomy. E-F, Immediate postoperative view of the visor osteotomy. G-H, Two years after treatment. 


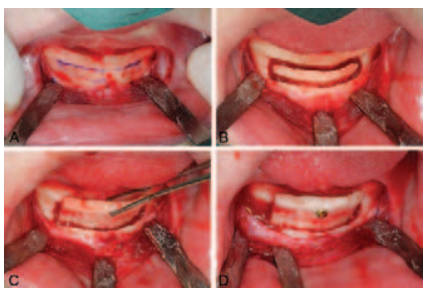

FIGURE 2. A, Intraoperative view of the chin region, with the incision line. B The visor osteotomy is performed. C-D, The bone fragment is mobilized and fixed in correct position.

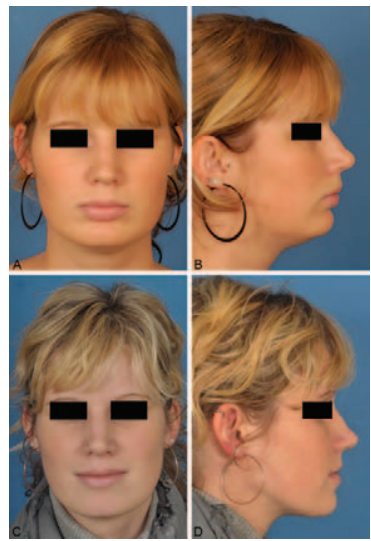

FIGURE 3. A-B, Frontal and lateral view of the face before treatment. C-D, Postoperative facial pictures show the appearance of the profile has improved.

was designed to create aesthetic mentolabial anatomy and a competent labial seal.

Coronal positioning of the pedicled bone fragment in the anterior mandible avoided the morbidity associated with the second surgical site and shortened treatment time. Large advancement genioplasties may be performed by leaving the musculoperiosteal pedicle attached to the advanced bony segment. ${ }^{2}$ The broadest possible musculoperiosteal pedicle should protect against infection, minimize the amount of bone resorbtion in the postoperative period, and make soft-tissue changes more predictable. ${ }^{14}$ A larger block dimension may be used to cover the dental roots and increase overall support for the area of the mentolabial fold. Stable osteosynthesis can be achieved by compressing a large surface area in contact with the underlying bone. The autogenous particulate marrow graft can be placed in the remaining gap, between the segments, to stimulate osteogenesis. Both osteotomized bone fragment and a harvested bone graft can be fixed with a plate. The bony step is rounded off because a peripheral part of the graft is resorbed. Hitherto, visor osteotomy was performed in 4 patients exclusively and in 7 patients adjuvant to the SSAO. To appropriately address the functional and aesthetic results, more patients will be closely followed on the long term.

\section{REFERENCES}

1. Obwegeser H, Trauner R. Zur Operationstechnik bei der Progenie und anderen Unterkieferanomalien. Dtsch Zahn-Mund-Kieferheilkd 1955;23:1-26

2. Polido WD, de Clairefont Regis L, Bell WH. Bone resorption, stability, and soft-tissue changes following large chin advancements. J Oral Maxillofac Surg 1991;49:251-256

3. Dolce C, Hatch JP, Van Sickels JE, et al. Five-year outcome and predictability of soft tissue profiles when wire or rigid fixation is used in mandibular advancement surgery. Am J Orthod Dentofacial Orthop 2003;124:249-256
4. Joss CU, Joss-Vassalli IM, Kiliaridis S, et al. Soft tissue profile changes after bilateral sagittal split osteotomy for mandibular advancement: a systematic review. J Oral Maxillofac Surg 2010;68:1260-1269

5. Satoh K, Mitsukawa N. Mandibular marginal contouring in oriental aesthetic surgery: refined surgical concept and operative procedure. Ann Plast Surg 2014;72:498-502

6. González-Ulloa M. Ptosis of the chin. The witches' chin. Plast Reconstr Surg 1972;50:54-57

7. Matsushita K, Inoue N, Yamaguchi HO, et al. Chin augmentation with thin cortical bone concomitant with advancement genioplasty. J Oral Maxillofac Surg 2010;68:691-695

8. Gamboa GM, Ross WA. Autogenous fat transfer in aesthetic facial reconstruction. Ann Plast Surg 2013;70:513-516

9. Matarasso A, Elias AC, Elias RL. Labial incompetence: a marker for progressive bone resorption in silastic chin augmentation: an update. Plast Reconstr Surg 2003;112:676-678

10. Celik M, Tuncer S, Büyükcayir I. Splitting advancement genioplasty: a new genioplasty technique. Ann Plast Surg 1999;43:148-153

11. Triaca A, Minoretti R, Saulacic N. Mandibula wing osteotomy for correction of the mandibular plane: a case report. Br J Oral Maxillofac Surg 2010;48:182-184

12. Härle F. Visor osteotomy to increase the absolute height of the atrophied mandible. A preliminary report. J Maxillofac Surg 1975;3:257-260

13. Peterson LJ. Augmentation of the mandibular residual ridge by a modified visor osteotomy. J Oral Maxillofac Surg 1983;41:332-338

14. Ellis E 3rd, Dechow PC, McNamara JA Jr, et al. Advancement genioplasty with and without soft tissue pedicle: an experimental investigation. J Oral Maxillofac Surg 1984;42:637-645

\section{Complete Removal of External Nasal Neurofibroma by Endonasal Approach}

Kyung Soo Kim, MD

Abstract: Although neurofibroma can develop in every possible anatomic location, neurofibroma originating from the external nose is extremely rare, and to our knowledge, only 2 cases have been reported so far in the English literature. In this report, the authors experienced a solitary neurofibroma originating from the external nose, which was successfully removed by endonasal approach (marginal incision).

Key Words: Endonasal approach, external nose, neurofibroma

$\mathrm{N}$ eurofibroma is localized, benign peripheral nerve sheath tumors caused by a combined proliferation of several elements of a peripheral nerve, including axons, schwann cells, fibroblasts,

From the Department of Otorhinolaryngology-Head and Neck Surgery, Chung-Ang University College of Medicine, Heukseok-dong, Dongjakgu, Seoul, South Korea.

Received March 2, 2015.

Accepted for publication May 3, 2015.

Address correspondence and reprint requests to Kyung Soo Kim, MD, PhD, Department of Otorhinolaryngology-Head and Neck Surgery, ChungAng University College of Medicine, 224-1, Heukseok-dong, Dongjakgu, Seoul, South Korea; E-mail: 99-21045@hanmail.net

The author reports no conflicts of interest.

Copyright $\odot 2015$ by Mutaz B. Habal, MD

ISSN: 1049-2275

DOI: $10.1097 /$ SCS.0000000000001961 


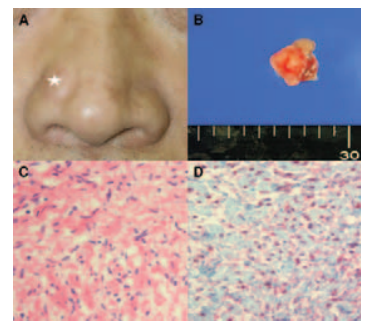

FIGURE 1. A, Clinical photograph showed that the mass (white star) was soft, nontender and rubbery, but not fixed to the underlying structure. The mass was located between upper and lower lateral cartilage. B, On macroscopic view of completely removed mass, the pale whitish gelatinous tissue was irregular surfaced and not encapsulated. C, The histologic examination of the mass showed combined proliferation of eosinophilic, thin, wavy collagen fibers lying in a disorderly pattern, and small spindleshaped cells without atypism. (hematoxylin and eosin stain $(\times 200)$ ). D, The spindle-shaped tumor cells revealed immunoreactivity for S-100 protein $(\times 400)$.

perineural cells, and endoneurium. ${ }^{1,2}$ Although neurofibroma can develop in every possible anatomic location, neurofibroma originating from the external nose is extremely rare, and to our knowledge, only 2 cases have been reported so far in the English literature. ${ }^{2,3}$ In this report, we experienced a solitary neurofibroma originating from the external nose, which was successfully removed by endonasal approach. Also, we review the literature of this rare but interesting lesion focusing on the difference from neurofibromas occurring in other sites.

\section{CLINICAL REPORT}

A 60-year-old man presented with a slowly and progressive growing mass involving over the right nasal ala of several years duration. He also complained of cosmetic problem. There was no history of trauma or previous surgical manipulation in this area. He had no nasal symptoms, such as epistaxis, nasal obstruction, or pain. He had no family history of similar diseases and no skin pigmentation or nodule. The mass was soft, not fixed to the underlying structure and nontender and did not respond to antibiotic treatment. In the nasal cavity, no abnormal finding was noted except the mildly bulging of the right nasal vestibule. Mass resection was performed via a marginal incision. The mass was located between upper and lower lateral cartilage (Fig. 1A)). En bloc resection of the tumor was performed to reveal a $2.0 \times 1.5 \times 0.8 \mathrm{~cm}$ mass (Fig. 1B). In macroscopic view, the pale whitish gelatinous tissue was not encapsulated and irregular surfaced. Histologic examination of the mass by hematoxylin and eosin staining showed the combined proliferation of eosinophilic, thin, wavy collagen fibers lying in a disorderly pattern with interlacing bundles of spindleshaped cells having wavy, hyperchromatic serpentine nuclei (Fig. 1C). Mitoses were not observed. Immnunohistochemistry with S-100 protein showed that these spindle-shaped cells were immunoreactive (Fig. 1D). The final pathologic diagnosis was neurofibroma. Surgery resulted in an excellent functional and cosmetic outcome. There are no signs of recurrence during a follow-up period of 18 months.

\section{DISCUSSION}

The clinical significance of this case report is because of its rare site. There have been only 2 reports concerning neurofibroma arising from the external nose (nasal tip, ${ }^{2}$ nasal dorsum). ${ }^{3}$ In this case, the origin of the tumor may be the external nasal branch of the anterior ethmoid nerve (ophthalmic nerve) depending the innervation of external nose innervation.

Depending on their location and size and involvement of surrounding structures, neurofibromas of the nasal cavity and paranasal sinuses may present with a variety of signs and nonspecific symptoms, such as nasal obstruction, epistaxis, and compressive symptoms. ${ }^{4}$ Neurofibromas of the external nose, however, may be present with cosmetic deformity because of tumor growth. ${ }^{2,3}$ In the current case, the primary complaint was cosmetic deformity as previously reported 2 cases.

The diagnosis of neurofibroma can be confirmed by the histopathologic findings, which are characterized by interlaced bundles of slender spindle cells with wavy dark-stained nuclei, collagen bundles and myxoid stroma and immunoreactivity of S-100 protein, neuron specific enolase (NSE), and vimentin. $^{3-5}$

The mainstay of the treatment is complete surgical excision of the tumor and close follow-up because neurofibromas may infiltrate extensively and have the possibility of malignant transformation. ${ }^{3,6}$ The best surgical approach for resection is dependent on the extent and the location of the tumor. If not excised completely, neurofibromas may recur locally and require further local resection. ${ }^{4}$ Also, functional and cosmetic considerations should be taken into account, especially neurofibroma originating from the external nose, like in the current case. In previously reported 2 cases, En bloc surgical resection of the mass was achieved by open rhinoplasty approach. ${ }^{2,3}$

Open rhinoplasty approach has some advantages for resection; the widest surgical exposure, safe and effective for complete tumor excision, and direct access for any possible reconstructive procedures that may be needed. ${ }^{2}$ In the current case, we, however, removed completely the mass by intranasal approach through marginal incision.

We suggest that intranasal approach through marginal incision or intercartilaginous incision can be used in the treatment for neurofibroma originating from the external nose when the mass is confined unilaterally and shows a distinct boundary.

In conclusion, this case highlights the importance of considering this clinical entity in the differential diagnosis of soft tissue mass in the external nose and choosing the best surgical approach to maintain a proper function and aesthetic appearance of the nose (Table 1).

\begin{tabular}{|c|c|c|c|c|c|c|}
\hline Author & Age/Sex & Site & Symptoms & Duration & Surgical Approach & Type \\
\hline Lee et $\mathrm{al}^{3}$ & $7 / \mathrm{F}$ & $\begin{array}{l}\text { Right side of the nasal dorsum: } \\
\text { both lower lateral cartilages }\end{array}$ & Progressive nasal swelling & 2 years & Open rhinoplasty approach & Solitary \\
\hline Rameh et $\mathrm{al}^{2}$ & $11 / \mathrm{M}$ & Nasal tip, supratip region & $\begin{array}{l}\text { Diffuse, nontender, } \\
\text { progressive growing mass }\end{array}$ & Several years & Open rhinoplasty approach & $\begin{array}{l}\text { Solitary } \\
\text { plexiform }\end{array}$ \\
\hline Current case & $60 / \mathrm{M}$ & Right side of nasal ala & Slowly and progressive growing mass & Several years & $\begin{array}{l}\text { Intranasal approach, } \\
\text { marginal incision }\end{array}$ & Solitary \\
\hline
\end{tabular}




\section{REFERENCES}

1. Ferner R, O’Doherty M. Neurofibroma and schwannoma. Curr Opin Neurol 2000;15:679-684

2. Rameh C, Husseini S, Tawil A, et al. Solitary plexiform neurofibroma of the nasal tip: case report and review of the literature. Int $J$ Pediatr Otorhinolaryngol Extra 2007;2:116-119

3. Lee JH, Bae JH, Kim KS. A case of solitary neurofibroma of the nasal dorsum: resection using an external rhinoplasty approach. Eur Arch Otorhinolaryngol 2005;262:813-815

4. Perzin KH, Panyu H, Wechter S. Nonepithelial tumors of the nasal cavity, paranasal sinuses and nasopharynx: a clinicopathological study. XII: Schwann cell tumors (neurilemoma, neurofibroma, malignant schwannoma). Cancer 1982;50:2193-2202

5. Miettinen M, Weiss SW. Soft tissue tumors. In: Damjanov I, Linder J, eds. Anderson's Pathology. 10th ed. St. Louis: Mosby-Year Book Inc; 1996. 2507-2510

6. Fisher ER, Vuzevski VD. Cytogenesis of schwannoma (neurilemoma), neurofibroma, dermatofibroma and dermatofibrosarcoma, as revealed by electron microscopy. Am J Clin Pathol 1968;49:141-145

\section{Correlation Between Blood Loss and Patient-Related Factors in the Bilateral Parasymphyseal Osteotomy}

\author{
Chun-Ming Chen, MDS, * Steven Lai, DDS, \\ Yea-Yin Yen, PhD, "Hong-Sen Chen, PhD, ${ }^{\dagger}$ \\ Ker-Kong Chen, PhD, ${ }^{\ddagger}$ and Kun-Jung Hsu, MDS $S^{\S}$
}

\begin{abstract}
The aim of this study was to determine the correlation between pre- and postsurgical loss of blood and blood components among patients undergoing treatment of facial deformities by bilateral parasymphyseal osteotomy (BPsO). The pre- and postoperative values of blood components were determined in 30 facial deformity patients who underwent orthognathic surgery by hypotensive anesthesia. Correlations among the blood loss, sex, age, operation time, and reduced values of blood components were assessed by a correlation matrix.

The mean blood loss and operation time were $437.5( \pm 52.5) \mathrm{mL}$ and $355.8( \pm 209.42)$ minutes, respectively. Two patients included in this study had required blood transfusion. The mean reduced red blood cell $\left(\times 10^{6} / \mu \mathrm{L}\right)$, hemoglobin $(\mathrm{g} / \mathrm{dL})$, and hematocrit $(\%)$ were $-1.02,-2.98$, and -9.18 , respectively. There was no significant correlation between blood loss and other related factors (eg, age,

From the *Departments of Oral and Maxillofacial Surgery; †Pediatric Dentistry; †Conservative Dentistry; §Family Dentistry, Kaohsiung Medical University Hospital, Kaohsiung Medical University, Kaohsiung, Taiwan; and IIDepartment of Oral Hygiene, College of Dental Medicine, Kaohsiung Medical University, Kaohsiung, Taiwan.

Received December 15, 2011.

Accepted for publication May 8, 2012.

Address correspondence and reprint request to Kun-Jung Hsu, MDS Department of Family Dentistry, Kaohsiung Medical University Hospital, No.100 Tzyou 1st Road, San Ming District, Kaohsiung 807, Taiwan; E-mail: taihen.n4545@msa.hinet.net

Kun-Jung Hsu and Ker-Kong Chen contributed equally to this work.

The authors report no conflicts of interest.

Copyright (C) 2015 by Mutaz B. Habal, MD

ISSN: 1049-2275
\end{abstract}

DOI: $10.1097 /$ SCS.0000000000000145 operation time, and reduced blood components). All patients, however, showed significantly lower values of blood components after surgery.

In conclusion, no significant factor was associated with blood loss and reduced blood components among patients undergoing BPsO. Furthermore, hypotensive anesthesia is a well-accepted method to reduce blood loss during orthognathic surgery.

Key Words: Blood loss, hypotensive anesthesia, operation time, orthognathic surgery

$\mathrm{O}$ rthognathic surgery has been extensively used for treating patients with facial deformities, and it requires highly skilled surgeons. The excessive blood supply to the craniofacial region presents a potential risk of massive blood loss during orthognathic surgery. Besides acknowledging the importance of appropriate planning and surgical precision, the surgeon should also be aware of other significant parameters that can influence treatment outcomes such as the physical condition of the patients, preoperative blood counts, operation duration, and amount of intraoperative blood loss. Therefore, patients should be provided essential information regarding compulsory blood transfusion and surgery-related risks for the different types of orthognathic surgery. For this reason, the application of general anesthesia in low blood pressure conditions has increased widely to reduce the need for blood transfusion, especially in the case of craniofacial surgery. The quantitative differences in bleeding among the different types of orthognathic surgery, however, have not been formally assessed.

Autogenous blood transfusion is being considered and applied by an increasing number of patients and surgeons. This is mainly a precautionary measure to prevent patients from acquiring transfusion-related diseases such as acquired immunodeficiency syndrome. Bilateral parasymphyseal osteotomy $(\mathrm{BPsO})$ is a modification of anterior subapical osteotomy (ASO) of the mandible. In BPsO, the bilateral vertical osteotomy lines are cut through to the inferior border without a horizontal ostoetomy. Bilateral parasymphyseal osteotomy combined with genioplasty can be used to treat a patient with severe chin deficiency. At the time of this writing, there is, however, no data available regarding variables related to blood loss and blood count in BPsO. Therefore, the purpose of the current study was to determine the correlation between blood loss and other factors such as the patient's characteristics, operating time, intraoperative blood loss, and pre- and postsurgical changes in blood components (red blood cell [RBC] count, hemoglobin $[\mathrm{Hb}]$, and hematocrit [Hct]) after BPsO.

\section{MATERIALS AND METHODS}

From 2000 to 2009, 30 patients participated in this study; these patients had undergone maxillary ASO and mandibular BPsO combined with genioplasty for the treatment of facial deformities, especially severe chin deficiency (Fig. 1). After nasotracheal intubation, all patients inhaled an anesthetic agent (sevoflurane). Blood gauze and suctioned blood were adjusted and determined. All operations were performed by same surgeon, and the same anesthesia protocols were used. The mean arterial pressure (MAP) of the patients was maintained at approximately $60 \mathrm{~mm} \mathrm{Hg}$. We retrospectively reviewed the charts, and the following data were recorded: patient's characteristics, operation time, intraoperative blood loss, and pre- and postsurgical changes in blood components (RBC count, $\mathrm{Hb}$, and $\mathrm{Hct}$ ). In the current study, statistical analysis was done using STATA Version 11.0. Descriptive analyses were carried out to examine the sample's background characteristics, blood loss level, operation time, and pre- and postsurgical blood 

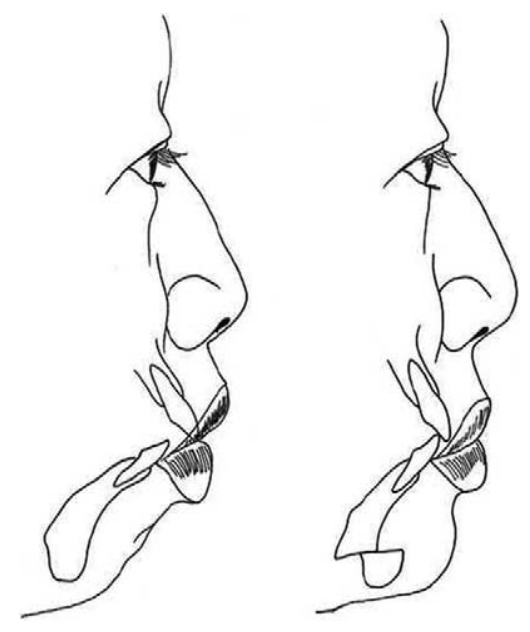

FIGURE 1. Left: preoperative profile-bimaxillary protrusion with chin deficiency; right: postoperative profile-anterior maxillary subapical osteotomy, bilateral parasymphysis osteotomy, and genioplasty.

components. The changes in blood components after surgery were calculated and analyzed by the paired $t$-test. The correlation matrix model was used to detect the correlations between blood loss and the other parameters such as the patient's characteristics, operation time, intraoperative blood loss, and pre- and postsurgical changes in blood components (RBC count, $\mathrm{Hb}$, and $\mathrm{Hct}$ ). A $P$ value $\leqq 0.05$ was considered significant. This study was approved by institutional review board (KMUH-IRB-990487) of our hospital.

\section{RESULTS}

The patients' characteristics are shown in Table 1. The study participants included 28 women and 2 men (mean age, $25.43 \mathrm{y}$; age range, $16-37 \mathrm{y}$ ). None of the patients had a history of coagulation deficiency or anticoagulation therapy. Two patients had received blood transfusion during hospitalization. Table 1 shows that mean operation time and blood loss were 437.5 $( \pm 52.5)$ minutes and $355.83( \pm 209.42) \mathrm{mL}$, respectively. Table 2 shows the various parameters of reduced blood components (RBC count, $\mathrm{Hb}$, and $\mathrm{Hct})$. The mean reduced $\mathrm{RBC}\left(\times 10^{6} / \mu \mathrm{L}\right), \mathrm{Hb}$ $(\mathrm{g} / \mathrm{dL})$, and Hct $(\%)$ were $-1.02,-2.98$, and -9.18 , respectively. The postsurgical changes in blood components ( $\mathrm{RBC}$ count, $\mathrm{Hb}$, and Hct) were significantly reduced. Correlation analyses between blood loss and the related factors (age, operation time, and reduced blood components) showed no significant relationship among the variables (Table 3 ).

TABLE 1. Descriptive Data of Operative Patients $(n=30)^{*}$

\begin{tabular}{lrrcc}
\hline Variables & Mean & SD & Minimum & Maximum \\
\hline Age, y & 25.43 & 4.70 & 16 & 37 \\
Blood loss, mL & 355.83 & 209.42 & 100 & 1025 \\
Operation time, min & 437.50 & 52.50 & 330 & 540 \\
Preoperation & & & & \\
$\quad \mathrm{RBC}, \times 10^{6} / \mu \mathrm{L}$ & 4.48 & 0.36 & 3.91 & 5.19 \\
$\mathrm{Hb}, \mathrm{g} / \mathrm{dL}$ & 13.24 & 1.38 & 9.3 & 16.3 \\
$\mathrm{Hct}, \%$ & 39.77 & 4.04 & 30.6 & 47.5 \\
Postoperation & & & & 4.25 \\
$\mathrm{RBC}, \times 10^{6} / \mu \mathrm{L}$ & 3.46 & 0.39 & 2.77 & 13.5 \\
$\mathrm{Hb}, \mathrm{g} / \mathrm{dL}$ & 10.26 & 1.28 & 8.2 & 38 \\
$\mathrm{Hct}, \%$ & 30.59 & 3.72 & 25.5 & \\
\hline
\end{tabular}

${ }^{*} \mathrm{n}$, number of patients.
TABLE 2. Postoperative Changes in the RBC, Hb, and Hct $(n=30)^{*}$

\begin{tabular}{lccc}
\hline Variables & Mean & SD & $P$ \\
\hline Reduced (postoperation-preoperation) & & \\
$\left.\mathrm{RBC}, \times 10^{6} / \mu \mathrm{L}\right)$ & -1.02 & 0.34 & $<0.0001$ \\
$\mathrm{Hb}, \mathrm{g} / \mathrm{dL}$ & -2.98 & 0.94 & $<0.0001$ \\
$\mathrm{Hct}, \%$ & -9.18 & 3.21 & $<0.0001$ \\
\hline
\end{tabular}

$\underset{*}{H b}$, hemoglobin; Hct, hematocrit; RBC, red blood cell.

$\mathrm{n}$, number of patients; by 1 -tailed paired $t$-test.

\section{DISCUSSION}

It is conceivable that the risk of blood loss and transfusion rates tend to increase if surgery is performed in the craniofacial region, which receives an abundant supply of blood. Nevertheless, the risk of potential blood loss during surgery and related risk factors associated with blood transfusion tend to be the main concern of surgeons and patients. The decision to carry out blood transfusion during orthognathic surgery should be based on a comprehensive evaluation of the patient. Patients must be aware of the potential for blood transfusion even if the physical condition of the patients does not indicate the necessity. Marciani and Dickson ${ }^{1}$ reported that the application of autogenous blood transfusion during surgery places the patients themselves at a relatively low risk. Obviously, autogenous blood transfusion is more beneficial than allogeneic blood transfusion. Neuwirth et $\mathrm{al}^{2}$ have reported that orthognathic patients with autogenous blood transfusion tend to recover and resume their daily activities much sooner than those who do not receive blood transfusion.

Marciani and Dickson ${ }^{1}$ have, however, reported a few drawbacks of autogenous blood donation, including the time consumed for preparation of autogenous blood donation, potential existence of microemboli and coagulopathic factors, risks of developing anemia or hypovolemia, and possibility of malpractice during the transfusion. In addition, autogenous blood donation may lead to a decrease in the preoperative Hct by $1 \%$ to $3 \%$ Hct per unit. ${ }^{3}$ Because blood transfusion requires at least 2 units of blood, patients must donate no less than the required amount to avoid allogeneic transfusion. The autogenous blood donation must be completed before the surgery to ensure that the plasma volume of patients returns to the normal level before the operation. Marciani and Dickson ${ }^{1}$ proposed that the interval between each autogenous blood donation should be at least 3 days, and the last donation should be no $<72$ hours before the surgery. Contrary to their suggestion, we do not routinely recommend preoperative autogenous blood donation, even in the case of 2 -jaw surgery. This is because patients may then require preoperative or intraoperative blood transfusion due to lower Hct after autogenous blood donation.

A thorough assessment of the preoperative data of patients is likely to evaluate the exact probability of blood transfusion. These data include blood cell count, Hct, body weight, calculated blood volume, minimum acceptable intraoperative and postoperative $\mathrm{Hb}$ and/or Hct, and the expected intraoperative blood loss. One needs to be very cautious because blood loss can have a significant impact on morbidity of physiological dysfunction and mortality after surgery. Meanwhile, whenever blood transfusion is indicated for surgery, the surgeon should verbally and documentarily inform the patient regarding the positive and negative aspects of autogenous as well as allogeneic blood transfusions.

Sollevi ${ }^{4}$ showed that the hazard of contracting various infectious diseases through blood transfusion indicates the importance of reducing the transfusion-associated risks by inducing hypotension. Nonetheless, hypotensive anesthesia needs to be performed only by those experienced professionals who are familiar with the contraindications of the manipulation and are also adequately adept and 
TABLE 3. Correlation Matrix

\begin{tabular}{|c|c|c|c|c|c|c|}
\hline Variables & Age & Blood Loss & Operation Time & Reduced RBC & Reduced Hb & Reduced Hct \\
\hline Age & 1 & -0.135 & 0.234 & -0.072 & -0.094 & -0.188 \\
\hline Blood loss & & 1 & -0.101 & -0.042 & -0.008 & -0.034 \\
\hline Operation time & & & 1 & -0.308 & -0.287 & -0.285 \\
\hline Reduced RBC & & & & 1 & $-0.969^{*}$ & $-0.0960^{*}$ \\
\hline Reduced $\mathrm{Hb}$ & & & & & 1 & $-0.0940^{*}$ \\
\hline Reduced Hct & & & & & & 1 \\
\hline
\end{tabular}

Spearman rho correlation. Hb, hemoglobin; Hct, hematocrit; RBC, red blood cell.

${ }^{*} P<0.05$.

careful with the monitoring systems to prevent occurrences of ischemia in the tissues. The application of induced hypotension to maintain the MAP at approximately $50 \mathrm{~mm} \mathrm{Hg}$ can effectively reduce the intraoperative blood loss and improve the visibility of the surgical field. Some caution, however, must be exercised as it is likely to be associated with a number of risks. The relevant complications include the decrease in tissue perfusion, shortage of oxygen delivery, quick oxygen debt, and drug toxicity.

During the surgery, careful application and monitoring of hypotensive anesthesia as well as thorough communication between the surgeon and anesthesiologist can have the following benefits: shortening of the duration of surgery, reducing the blood loss, and subsequently decreasing the potential for blood transfusion. This prudent practice also enables the surgeon to complete the operation without any complications. Consequently, inducing and controlling hypotensive anesthesia has been an inevitable and important task in orthognathic surgery. Many studies have revealed that hypotensive anesthesia can provide a clear operative field, and consequently reduce the operation duration, thereby avoiding the need for blood transfusion. Schaberg et $\mathrm{al}^{5}$ indicated that the application of hypotensive anesthesia can significantly reduce the surgical blood loss by $40 \%$ to $50 \%$. This is achieved by using systemic vasodilators, ganglionic blocking agents, and changing the posture of the patients to induce low blood pressure, to decrease blood perfusion over the regional tissues.

Hypotensive anesthesia seldom results in severe and irreversible damage because blood perfusion through the internal vascular networks is reasonably maintained. The estimated rate of occurrence of death and ischemic failure of internal organs caused by hypotensive anesthesia, however, ranges from $0.02 \%$ to $0.06 \%{ }^{6}$ If the hypotensive anesthesia can be maintained between 40 and $60 \mathrm{~mm} \mathrm{Hg}$, the microcirculation tends to restore and spontaneously adjust the perfusion volume within the internal organs such as the brain, heart, liver, and kidney. ${ }^{7}$ This circulatory function of selfregulated blood flow is maintained by intrinsic vasodilators, generated by the elastic smooth muscles of blood vessels and its metabolites activated within the tissues. The current studies ${ }^{3,8}$ reveal that the controlled hypotension required for maintaining MAP between 50 and $65 \mathrm{~mm} \mathrm{Hg}$ is clinically acceptable and safe for healthy young patients. Hypotensive anesthesia still presents potential life-threatening risks if the patients are aged and have a compromised physical condition. Although orthognathic surgery is mostly applied for young patients who are physically fit and present with well self-regulated physiological functions, some reports indicate that the induced blood hypoperfusion can still cause brain damage or neuronal dysfunction, stroke, arrhythmia, cardiac arrest, and even death in those patients with significant vascular or hematological diseases such as anemia.9,10

The definitive standard to determine whether blood transfusion must be implemented during surgery is quite different among the various oral and maxillofacial surgical teams. In the past decade, the tendency to restrict blood transfusion has been significantly increasing. A study by Gong et $\mathrm{al}^{11}$ showed that autogenous blood donation is not routinely required, even for double-jaw orthognathic surgery. Samman et $\mathrm{al}^{12}$ also found that it is not essential to carry out transfusion in single-jaw surgery. Furthermore, a study by Moenning et $\mathrm{a}^{13}$ indicated that only 4 among 506 patients treated with the 2 -jaw orthognathic surgery required blood transfusion. Moreover, a number of studies have shown that the routine preoperative autogenous blood donation is not required even with the double-jaw surgery. The Hb level of a healthy patient treated with the ordinary double-jaw orthognathic surgery is expected to decrease by 2 to $3 \mathrm{~g} /$ $\mathrm{dL}$. In our series, the $\mathrm{Hb}$ was reduced by $3 \mathrm{~g} / \mathrm{dL}$. Ueki et $\mathrm{al}^{14}$ examined 62 prognathic patients who underwent orthognathic surgery. They showed significant positive correlation between duration of operation and blood loss. Böttger et $\mathrm{al}^{15}$ performed retrospective analysis of for 65 patients who underwent autogenous blood transfusion in bimaxillary repositioning osteotomy surgery. There was only a weak correlation between the blood loss and duration of surgery. Our study also demonstrated no significant correlation between the blood loss and operation time.

In conclusion, hypotensive anesthesia could reduce the blood loss, which in turn minimizes transfusion-related risks, enhances surgical field, and reduces surgical time. Our study confirmed that no significant factor was associated with blood loss and reduced blood components during $\mathrm{BPsO}$ with hypotensive anesthesia.

\section{REFERENCES}

1. Marciani RD, Dickson LG. Autologous transfusion in orthognathic surgery. J Oral Maxillofac Surg 1985;43:201-204

2. Neuwirth BR, White RP Jr, Collins ML, et al. Recovery following orthognathic surgery and autologous blood transfusion. Int J Adult Orthodon Orthognath Surg 1992;7:221-228

3. Cohen JA, Brecher ME. Preoperative autologous blood donation: benefit or detriment? A mathematical analysis. Transfusion 1995;35:640-644

4. Sollevi A. Hypotensive anesthesia and blood loss. Acta Anaesthesiol Scand Suppl 1988;89:39-43

5. Schaberg SJ, Kelly JF, Terry BC, et al. Blood loss and hypotensive anaesthesia in oral-facial corrective surgery. J Oral Surg 1976;34:147156

6. Leigh JM. The history of controlled hypotension. Br J Anaesth 1975;47:745-749

7. Yamada S, Brauer F, Knierim D, et al. Safety limits of controlled hypotension in humans. Acta Neurochir Suppl 1988;42:14-17

8. Kurian A, Ward-Booth P. Blood transfusion and orthognathic surgerya thing of the past? Br J Oral Maxillofac Surg 2004;42:369-370

9. Choi WS, Samman N. Risks and benefits of deliberate hypotension in anaesthesia: a systematic review. Int J Oral Maxillofac Surg 2008;37:687-703

10. Pasch T, Huk W. Cerebral complications following induced hypotension. Eur J Anaesthesiol 1986;3:299-312 
11. Gong SG, Krishnan V, Waack D. Blood transfusions in bimaxillary orthognathic surgery: are they necessary? Int J Adult Orthodon Orthognath Surg 2002;17:314-317

12. Samman N, Cheung LK, Tong AC, et al. Blood loss and transfusion requirements in orthognatic surgery. J Oral Maxillofac Surg 1996;54:21-24

13. Moenning JE, Bussard DA, Lapp TH, et al. Average blood loss and the risk of requiring perioperative blood transfusion in 506 orthognathic surgical procedures. J Oral Maxillofac Surg 1995;53:880-883

14. Ueki K, Marukawa K, Shimada M, et al. The assessment of blood loss in orthognathic surgery for prognathia. J Oral Maxillofac Surg 2005;63:350-354

15. Böttger S, Streckbein P, Hartmann B, et al. Retrospective analysis of autologous blood use in bimaxillary repositioning osteotomy surgery: a quality improvement study. Transfusion 2009;49:1747-1753

\section{Short Lingual Osteotomy Using a Piezosurgery Ultrasonic Bone- Cutting Device During Sagittal Split Ramus Osteotomy}

Yoko Kawase-Koga, DDS, PhD, ${ }^{*}$ Yoshiyuki Mori, DDS, PhD, ${ }^{\dagger}$ Yuki Kanno, DDS, * Kazuto Hoshi, MD, PhD,*

and Tsuyoshi Takato, MD, PhD*

\begin{abstract}
Short lingual osteotomy is a useful method for the performance of sagittal split ramus osteotomy involving interference between the proximal and distal bone fragments when lateral differences exist in the setback distance. However, this procedure occasionally results in abnormal fracture and nerve injury; expert surgical skill is thus required. We herein describe a novel technique involving the use of an ultrasonic bone-cutting device (Piezosurgery; Mectron Medical Technology, Carasco, Italy) for vertical osteotomy posterior to the mandibular foramen. Successful short lingual osteotomy was performed using this technique with avoidance of abnormal fracture and neurovascular bundle damage.
\end{abstract}

Key Words: Short lingual osteotomy (SLO), sagittal split ramus osteotomy (SSRO), Piezosurgery

agittal split ramus osteotomy (SSRO) is a widely used surgical $S$ procedure for the treatment of jaw deformity in patients with mandibular prognathism. However, potential problems during SSRO include interference between the proximal and distal bone fragments when lateral differences exist in the setback distance, as well as

From the ${ }^{*}$ Department of Oral and Maxillofacial Surgery, Dentistry and Orthodontics, The University of Tokyo Hospital, Tokyo; and tDepartment of Dentistry, Oral and Maxillofacial Surgery, Jichi Medical Univeristy, Shimotsuke, Japan

Received February 7, 2014.

Accepted for publication January 20, 2015.

Address correspondence and reprint requests to Yoshiyuki Mori, DDS, $\mathrm{PhD}$, Department of Dentistry, Oral and Maxillofacial Surgery, Jichi Medical Univeristy, 3311-1 Yakushiji, Shimotsuke, Tochigi Prefecture 329-0498, Japan; E-mail: mori-ora@jichi.ac.jp

The authors report no conflict of interest.

Copyright 102015 by Mutaz B. Habal, MD

ISSN: 1049-2275

DOI: $10.1097 / \mathrm{SCS} .0000000000001590$ increased posterior projection of the distal bone fragment and difficulty splitting curved rami in cases involving a considerable setback distance. ${ }^{1}$ Short lingual osteotomy (SLO) is thus recommended as proposed by Epker et al, ${ }^{2,3}$ who performed horizontal osteotomy of the medial aspect of the ramus beyond the mandibular foramen without extending to the posterior border. However, this procedure is prone to abnormal fracture and nerve injury, ${ }^{4}$ and expert surgical skill is required. We herein describe the use of an ultrasonic bonecutting device (Piezosurgery; Mectron Medical Technology, Carasco, Italy), which is a useful instrument for soft-tissue protection, ${ }^{5}$ during vertical osteotomy posterior to the mandibular foramen for successful SLO without neurovascular bundle damage.

\section{CLINICAL REPORT}

Vertical osteotomy of the cortical bone on the medial aspect of the ramus was performed in close proximity to the mandibular foramen using an ultrasonic bone-cutting device to determine the posterior osteotomy boundary during SLO (setback amount, $\geq 5 \mathrm{~mm}$ ) in a patient undergoing SSRO for jaw deformity. After incising the mucosa of the anterior border of the ramus according to the standard SSRO procedure, ${ }^{6}$ the periosteum was detached from the inferior to the posterior border of the lateral aspect of the ramus. The periosteum was then detached from the medial aspect of the ramus, extending horizontally in a posterior direction from between the sigmoid notch and mandibular foramen up to the posterior border of the ramus. After applying retraction to the medial aspect of the ramus, the horizontal osteotomy region was specified on the cortical bone surface, and horizontal osteotomy was performed to close the mandibular foramen using a Lindemann bur. The cortical bone was cut from the lateral aspect of the anterior mandibular body to the medial aspect of the ramus using a reciprocating saw. Vertical osteotomy of about $10 \mathrm{~mm}$ was then conducted from the posterior edge of the horizontal osteotomy, in close proximity to the mandibular foramen, toward the inferior border using an ultrasonic bone-cutting device to split the sagittal surface of the ramus (Figs. 1 and 2). The present method appeared to be particularly useful in this region because retraction of the neurovascular bundle is especially challenging, and conventional cutting equipment carries a high risk of soft-tissue damage. The cortical bone on the medial aspect of the posterior ramus was split sagittally while being maintained by the proximal bone fragment (Fig. 3). Intraoperative intermaxillary

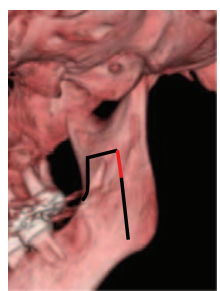

FIGURE 1. Osteotomy lines on the medial aspect of the ramus. Black solid line: osteotomy performed using a conventional cutting device. Red solid line: osteotomy performed using an ultrasonic bone-cutting device (approximately $10 \mathrm{~mm}$ ). Black dotted line: split using a bone chisel.

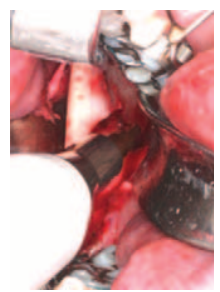

FIGURE 2. Posterior vertical osteotomy of the medial aspect of the ramus using an ultrasonic bone-cutting device. 


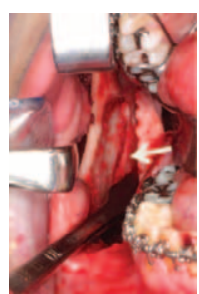

FIGURE 3. The ramus following sagittal splitting. Arrow: residual cortical bone on the posterior medial aspect of the proximal bone fragment.

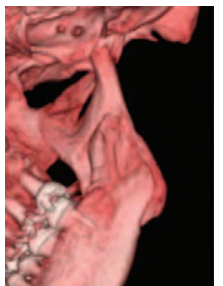

FIGURE 4. Three-dimensional computed tomography 1 month postoperatively. Posterior projection of the distal bone fragment is not observed with an 8.0-mm setback.

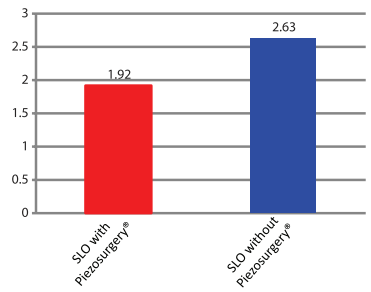

FIGURE 5. Neurosensory results revealed an average force of 1.92 and 2.63 Fmg with and without the Piezosurgery device, respectively $(P=0.105)$.

fixation was conducted, and the bone fragments were fixed using titanium miniplates. Postoperative occlusion was stabilized using intermaxillary elastics. Postoperative computed tomography revealed that the posterior edge of the distal bone fragment did not project posteriorly beyond the proximal bone fragment (Fig. 4). To identify the presence of neurosensory damage during SLO using the Piezosurgery device, we investigated the neurosensory status of the mental nerve in patients who underwent SLO with the Piezosurgery device (17 sides) and without the Piezosurgery device (as a control: 9 sides) 4 weeks postoperatively using a SemmesWeinstein pressure esthesiometer (Research Design, Inc, Houston, TX). This esthesiometer comprises 20 individual filaments with different diameters labeled with filament marking values (Fmg) ranging from 1.65 to 6.65 . The neurosensory results revealed an average force of 1.92 and $2.63 \mathrm{Fmg}$ with and without the Piezosurgery device, respectively $(P=0.105)$ (Fig. 5). These results indicate that the use of the Piezosurgery device effectively protects against neurovascular bundle damage. Moreover, to evaluate the effect of operative duration using the Piezosurgery device, we compared the surgical time among patients described above who underwent bilateral sagittal split osteotomy (BSSO) alone or BSSO and Le Fort I osteotomy with and without the Piezosurgery device. In patients with BSSO alone (with Piezosurgery: 8 cases, without Piezosurgery: 3 cases), the average of surgical time indicated 3 hours 23 minutes and 4 hours 3 minutes with and without the Piezosurgery device $(P=0.09)$. In patients with BSSO and Le Fort I osteotomy (with Piezosurgery: 5 cases, without Piezosurgery: 4 cases), the average of surgical time indicated 6 hours 39 minutes and 6 hours 45 minutes with and without the Piezosurgery device $(P=0.36)$. These results suggest that use of Piezosurgery device does not affect an extension of operative duration of SLO.

\section{DISCUSSION}

In patients with mandibular prognathism, orthognathic surgery is required to produce functionally and aesthetically satisfactory results with no complications. Therefore, oral and maxillofacial surgeons continue to develop novel methods to obtain successful outcomes and good long-term results. Sagittal split ramus osteotomy is widely used to treat jaw deformity in patients with mandibular prognathism. Moreover, SLO is performed to prevent interference between the proximal and distal bone fragments when lateral differences exist in the setback distance, as well as in cases involving increased posterior projection of the distal bone fragment and difficulty splitting curved rami when a considerable setback distance exists. ${ }^{2,3}$ However, no safe method of preventing abnormal fracture and nerve injury has been reported. Several clinical studies have demonstrated that the ultrasonic bone-cutting device has advantages over the use of saws or burs. ${ }^{7-10}$ In the current study, posterior vertical osteotomy of the medial aspect of the ramus using an ultrasonic bone-cutting device enabled successful SLO and simplified mandibular setback while minimizing postoperative inferior alveolar nerve damage. Moreover, our procedure with Piezosurgery device resulted in shorter operation time. Generally, use of Piezosurgery device-induced operation time is slightly longer than conventional saw. ${ }^{5}$ In our procedure, Piezosurgery device performs only about $10 \mathrm{~mm}$ of vertical osteotomy for a few minutes to make the posterior edge of the horizontal osteotomy; consequently, use of Piezosurgery device does not affect an extension of operative duration of SLO. Furthermore, adding vertical osteotomy with Piezosurgery device split bone easily in SLO.

In conclusion, the present technique provides a method of preventing posterior projection of the distal bone fragment during mandibular setback, avoiding bone fragment interference and safely achieving SSRO even in patients with a curved ramus, indicating the use of this approach for SLO.

\section{REFERENCES}

1. Yang HJ, Lee WJ, Yi WJ, et al. Interferences between mandibular proximal and distal segments in orthognathic surgery for patients with asymmetric mandibular prognathism depending on different osteotomy techniques. Oral Surg Oral Med Oral Pathol Oral Radiol Endod 2010;110:18-24

2. Hunsuck EE. A modified intraoral sagittal splitting technic for correction of mandibular prognathism. J Oral Surg 1968;26:250254

3. Epker BN. Modification in the sagittal osteotomy of the mandible. J Oral Surg 1977;35:157-159

4. Plooij JM, Naphausen MT, Maal TJ, et al. 3D evaluation of the lingual fracture line after a bilateral sagittal split osteotomy of the mandible. Int J Oral Maxillofac Surg 2009;38:1244-1249

5. Labanca M, Azzola F, Vinci R, et al. Piezoelectric surgery: twenty years of use. Br J Oral Maxillofac Surg 2008;46:265-269

6. Trauner R, Obwegeser H. The surgical correction of mandibular prognathism and retrognathia with consideration of genioplasty. I. Surgical procedures to correct mandibular prognathism and reshaping of the chin. Oral Surg Oral Med Oral Pathol 1957;10:677-689

7. Landes CA, Stubinger S, Ballon A, et al. Piezoosteotomy in orthognathic surgery versus conventional saw and chisel osteotomy. Oral Maxillofac Surg 2008;12:139-147

8. Landes CA, Stubinger S, Rieger J, et al. Critical evaluation of piezoelectric osteotomy in orthognathic surgery operative technique, blood loss, time requirement, nerve and vessel integrity. J Oral Maxillofac Surg 2008;66:657-674

9. Sakkas N, Otten J, Gutwald R, et al. Transposition of the mental nerve by Piezosurgery followed by postoperative neurosensory control: a case report. Br J Oral Maxillofac Surg 2008;46:270-271

10. Pavlíková G, Foltán R, Horká M, et al. Piezosurgery in oral and maxillofacial surgery. Int J Oral Maxillofac Surg 2010;40:451-457 


\section{Accuracy of Marginal Reflex Distance Measurements in Eyelid Surgery}

Arie $Y$. Nemet, $M D$

Purpose: The marginal reflex distance (MRD), the position of the eyelids with the eyes in the primary position, is fundamental to patient assessment and surgery choice in facial and ophthalmic plastic surgery. This study compares the accuracy of handheld ruler and slit lamp biomicroscope measurements of the $\mathrm{MRD}_{1}$ in patients with blepharoptosis.

Methods: This is a prospective study of 85 consecutive patients who were referred to our oculoplastic clinic between 2011 and 2013 for unilateral or bilateral ptosis repair.

The $\mathrm{MRD}_{1}$ was measured by 2 techniques:

1. With the use of a penlight to illuminate the cornea, the corneal light reflex is observed, and the distance between the cornea and the upper lid margin is recorded.

2. Slit lamp biomicroscope assessment.

A comparison between those 2 methods was performed.

Results: The mean (SD) $\mathrm{MRD}_{1}$ was 1.18 (1.11) mm and 1.06 (1.18) $\mathrm{mm}$ with a penlight and a slit lamp, respectively. There was a significant difference between the 2 measurements, but they were highly correlated in the paired $t$-test and the Wilcoxon test. The intraclass correlation coefficient was 0.984 , representing excellent reliability. Conclusions: The $\mathrm{MRD}_{1}$ measured by a skilled clinician yields reliable results using a penlight and a ruler. In some cases, measurement of eyelid heights (palpebral fissure, $\mathrm{MRD}_{1}$, brow position) is challenging. The use of a slit lamp biomicroscope and a close front photograph may help determine accurate measurements.

Key Words: Eyelid surgery, marginal reflex distance, measurements, ptosis

$T$ he measurement of certain eyelid parameters is fundamental to patient assessment and the type of procedure in facial and ophthalmic plastic surgery. ${ }^{1}$ These include upper eyelid levator muscle function, brow position, marginal reflex distance (MRD), ${ }^{2,3}$ position of the eyelids with the eyes in the primary position, and the level of the upper lid skin crease. ${ }^{4,5}$ Incorrect values may lead to the wrong diagnosis or to an inappropriate operation. Lid height or palpebral fissure (PF) is the distance from the bottom of the upper eyelid margin to the top of the bottom eyelid margin taken at the center of the eyelid. It is composed of the addition of $\mathrm{MRD}_{1}$ and $\mathrm{MRD}_{2}$ (Fig. 1). ${ }^{6,7}$ The $\mathrm{MRD}_{1}$ (the distance from the center of the pupil to the upper eyelid) has specific importance in planning surgery. ${ }^{3,6}$ It is influenced by the brow position, by the skin and orbicularis mass, sympathetically by the Muller muscle, as well as by the levator aponeurosis. Any difference in MRD between the eyes needs correction during surgery,

From the Department of Ophthalmology, Meir Medical Center, Kfar Sava, Israel.

Received January 1, 2014.

Accepted for publication August 19, 2014.

Address correspondence and reprint requests to Arie Y. Nemet, MD,

Department of Ophthalmology, Meir Medical Center, Tchernichovsky

59 Kfar Sava, Israel 4428164; E-mail: nemet.arik@gmail.com

The author reports no conflicts of interest.

Copyright (1) 2015 by Mutaz B. Habal, MD

ISSN: 1049-2275

DOI: $10.1097 /$ SCS.0000000000001304

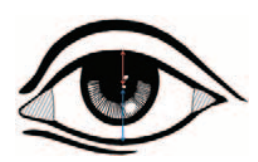

FIGURE 1. The $\mathrm{MRD}_{1}$ is the distance between the center of the pupillary light reflex and the upper eyelid margin with the eye in primary gaze. The $M R D_{2}$ is the distance between the center of the pupillary light reflex and the lower eyelid margin with the eye in primary gaze.

and even minor postoperative inaccuracy is significant and seen by the surgeon, the patient, and observers.

Traditionally, these preoperative measurements have been obtained by the clinician using a handheld ruler. It has been suggested that, with the use of a standardized hand measurement protocol, intraobserver and interobserver variability are low. ${ }^{8}$ However, there is some evidence of learning curve effects, both short- and long-term, and suggestion of greater agreement at extremes of levator function. ${ }^{8}$ Measures of MRD are fraught with potential confounders, chief among which is the patient's response to light. When a patient is asked to look at an object (light or otherwise), the eyes open slightly. More importantly, when light is shined in the eyes to measure MRD, patients will squint. A penlight should be shined on the forehead to mitigate this.

The slit lamp instrument consists of a high-intensity light source that can be controlled and focused to shine a thin sheet of light into the eye. It is used in conjunction with a biomicroscope. The lamp facilitates examination of the anterior and posterior segments of the eye, including the eyelids. It supplies magnification from $\times 10$ to approximately $\times 50$ (depending on the model). Hence, it can accurately measure the $\mathrm{MRD}_{1}$ in millimeters. The purpose of the current study was to examine the accuracy of a handheld ruler compared with slit lamp measurement of the $\mathrm{MRD}_{1}$ in patients with blepharoptosis.

\section{MATERIALS AND METHODS}

\section{Study Population}

We prospectively measured all consecutive patients referred to our oculoplastic clinic from 2011 through 2013 for unilateral or bilateral ptosis repair. Cases were considered as ptotic when the $\mathrm{MRD}_{1}$ was less than $2 \mathrm{~mm}$ or when the difference between the eyelid positions was $2 \mathrm{~mm}$ or more (excluding cases of lid retraction). The study was approved by the local institutional review board.

All examinations were performed by the same examiner (AYN), with the patient's head posture, gaze, and camera position standardized to provide a reproducible, accurate photograph of the eyelids. The eyelid evaluation included clinical assessment of the $\mathrm{MRD}_{1}$, the levator function, the PF, and the existence of Bell phenomenon.

The $\mathrm{MRD}_{1}$ was measured by 2 techniques. First, with the use of a penlight to illuminate the cornea, the observer fixates the brow on the side being measured or lifts the brow on the opposite side, so the patient does not raise the ptotic lid. The corneal light reflex is observed, and the distance between the cornea and the upper lid margin is recorded. This corresponds to the upper eyelid resting at or slightly below the superior corneal limbus. When the degree of ptosis is severe and the upper lid obstructs the corneal light reflex, the measurement will assume a negative value. This measurement is independent of variations in the position of the lower eyelid. ${ }^{9}$ This measurement was in $0.5-\mathrm{mm}$ increments.

The second measurement was a slit lamp assessment, with the patient sitting upright and the slit lamp focused on the eyelids as they are opened. The distance between the light reflex and the upper eyelid margin is measured accurately (can be measured in increments of $0.1 \mathrm{~mm}$ ) (Fig. 2). A front face photograph and a close slit lamp photograph were taken for each patient to validate the measurements and the results. 
(a)

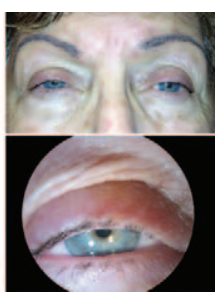

FIGURE 2. A, A 74-year-old woman with bilateral ptosis. The measurement with a ruler and a lamp is $0.5 \mathrm{~mm} \mathrm{MRD}$ in the right eye and $1 \mathrm{~mm}$ in the left eye. Note the excess effort in the right brow (frontalis muscle) to compensate for the eyelid ptosis. B, A slit lamp photograph of the right eye of the same patient, which controls the brow compensation. It gives a more accurate measurement of $0.0 \mathrm{~mm} \mathrm{MRD_{1 }}$

\section{Statistical Analysis}

The difference between the 2 measurements was analyzed using the paired $t$-test. The correlation between the 2 measurements was calculated using the Pearson correlation. The intraclass correlation coefficient (ICC), which measures the consistency of measures, was also calculated. A Bland-Altman plot (a graphical method to compare 2 measurement techniques) was done to measure agreement between the 2 methods. Results were considered statistically significant when $P<0.05$. Data were analyzed using SPSS-21 statistical software.

\section{RESULTS}

A total of 85 patients with unilateral or bilateral ptosis were included in the study. There were 44 women and 41 men, with a mean (SD) age of 62.9 (17.6) years. Fifty-two patients had bilateral ptosis, and 33 had unilateral ptosis.

The mean (SD) $\mathrm{MRD}_{1}$ was $1.18(1.11) \mathrm{mm}$ and $1.06(1.18) \mathrm{mm}$ for the penlight and slit lamp examinations, respectively $(p<0.0001)$. The correlation between the measurements was high $(r=0.970$, $p<0.0001)$. The ICC was 0.984 , which represents excellent reliability (Fig. 2). The Bland-Altman plot (Fig. 3) shows that only 4 of 85 paired measurements exceeded the limits of agreement (Fig. 4).

\section{DISCUSSION}

When examining a patient who has dermatochalasis or blepharoptosis, several important measurements must be made that are critical to management and have a direct impact on surgical planning. ${ }^{4}$ Preoperative asymmetry assessment is of utmost importance to achieve postoperative symmetry. Before Putterman and Urist $^{3}$ described the $\mathrm{MRD}_{1}$ measurement, the traditional way to measure the amount of blepharoptosis was to measure the PF width in the primary gaze position. ${ }^{6}$ The $\mathrm{MRD}_{1}$ measures the amount of uppereyelid ptosis without regard to the position of the lower eyelid. ${ }^{3}$

The results here confirm the relative accuracy of a handheld ruler and penlight for the assessment of eyelid height. The difference found is attributed to the different increments in each measurement $(0.5 \mathrm{~mm}$ for the penlight and $0.1 \mathrm{~mm}$ for the slit lamp). The

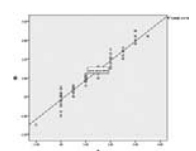

FIGURE 3. The ICC was 0.984 , which represents excellent reliability.

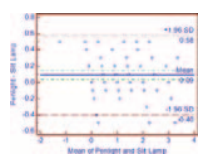

FIGURE 4. Bland-Altman plot of the penlight and slit lamp examinations.

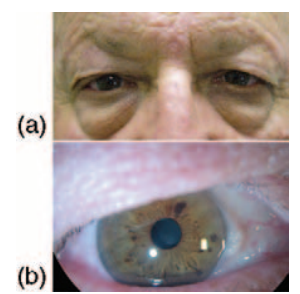

FIGURE 5. A, A 72-year-old man, front photograph, shows significant brow ptosis and dermatochalasis. The physician needs to lift the excess skin of the eyelid and press over the brow to get an accurate assessment of the eyelid height and the $\mathrm{MRD}_{1}$. B, A slit lamp photograph of the right eye of the same patient shows a higher magnification of the eyelid and easier measurements.

margin of error for ptosis that is clinically relevant is $0.5 \mathrm{~mm}$ because a difference of more than $0.5 \mathrm{~mm}$ is noticeable (Figs. 5 and 6).

Although the diagnosis of ptosis is based on the clinical evaluation of the patient, it is best defined in terms of the midpupil to upper lid distance $\left(\mathrm{MRD}_{1}\right){ }^{4}$ The $\mathrm{MRD}_{1}$ has specifically a significant importance in planning surgery. However, MRD measurements are tricky and require a high level of accuracy. The traditional measurement is obtained by the clinician using a handheld ruler, which can be highly variable. The MRD shows significant variation among select ethnic groups, ranging from a mean of $3.8 \mathrm{~mm}$ in Asian people to $5.1 \mathrm{~mm}$ in white people, with no difference between sexes within each ethnic group. ${ }^{10}$ It has been shown that interobserver and intraobserver variability in upper eyelid ptosis assessment, when conducted in a standardized fashion, are modest and clinically acceptable, particularly among clinicians of greater experience. ${ }^{8}$

Hence, the determination of what constitutes the normal position of the eyelid should be individualized to each patient, taking into account ethnicity, age, sex, other ophthalmic findings, patient expectations, and patient appearance in old photographs. ${ }^{10}$

We considered the slit lamp measurement as the more accurate method because of the following:

(1) It supplies a significantly higher magnification compared with hand measurements.

(2) The patient is opposing it, brow against the head rest, which prevents overreaction of the brow muscles.

(3) The patient is concentrated in the light coming from the illuminator, opening the eyes better, and is less dazzled with the light intensity of the penlight.

We used photographs to document the penlight and slit lamp measurements. Photography, digital or conventional, is regarded as an integral part of the plastic surgery patient's assessment and followup, especially in the context of the increasingly widespread use of electronic patient records. It gives reliable and accurate results. However, unless the same conditions are maintained before and after surgery, photographs can lose their relevance and overall impact. ${ }^{11}$

(a)

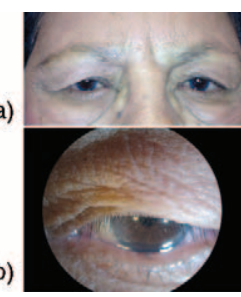

FIGURE 6. A, A 70-year-old woman, front photograph, shows significant dermatochalasis. The physician needs to lift the excess skin of the eyelid to obtain an accurate assessment of the eyelid height and the $\mathrm{MRD}_{1}$. B, A slit lamp photograph of the left eye of the same patient shows a higher magnification of the eyelid and easier measurements. 
Limitations and possible confounding factors to our findings should be considered. Marginal reflex distance measurements showed that only $22 \%$ of the variability is due to sex, ethnicity, and/or age; there may be other variables that were not taken into account. ${ }^{10}$ Measurement errors by the examiner are possible, but consistent and reproducible measurements have been seen in previous studies. ${ }^{12}$ Errors could have occurred if there was any deviation of the patient's eyes to the left or the right in the horizontal plane, artificially increasing fissure height measurements. ${ }^{8}$ Other height measurements could have been altered by the time of day because PF heights are reported to have peak heights occurring between $10 \mathrm{Am}$ and $10 \mathrm{PM},{ }^{13}$ and contradictory data exist regarding the influence of environment on anthropometric measurements. ${ }^{14}$

Despite the findings in this study, measurement of eyelid heights may be challenging, especially in patients with scoliosis, brow ptosis, deep eyes, or shallow orbits. One way to examine the patient without the slit lamp is by using a penlight, in which the intensity of the light can be regulated so it does not dazzle the patient (similar to controlling the intensity on the slit lamp). In those cases, the use of a slit lamp biomicroscope and a close front photograph may help determine accurate measurements.

\section{REFERENCES}

1. Collin JRO. Ptosis. In: A manual of systematic eyelid surgery. $2 \mathrm{nd}$ ed. London, England: Churchill Livingstone, 1989:41-72.

2. Putterman AM. Margin reflex distance (MRD) 1, 2, and 3. Ophthal Plast Reconstr Surg 2012; 28:308-311.

3. Putterman AM, Urist MJ. Muller muscle-conjunctiva resection. Technique for treatment of blepharoptosis. Arch Ophthalmol 1975;93:619-623

4. Small RG, Sabates NR, Burrows D. The measurement and definition of ptosis. Ophthal Plast Reconstr Surg 1989;5:171-175

5. Karesh JW. Diagnosis and management of acquired blepharoptosis and dermatochalasis. Facial Plast Surg 1994;10:185-201

6. Putterman AM. Margin reflex distance (MRD) 1,2, and 3. Ophthal Plast Reconstr Surg 2012;28:308-311

7. Nerad JA. Evaluation and treatment of the patient with ptosis. In: Krachner JH, ed. Oculoplastic Surgery: the requisites in ophthalmology. St Louis, MO: Mosby Inc, 2001:157-192.

8. Boboridis K, Assi A, Indar A, et al. Repeatability and reproducibility of upper eyelid measurements. Br J Ophthalmol 2001;85:99-101

9. Ahmad SM, Della Rocca RC. Blepharoptosis: evaluation, techniques, and complications. Facial Plast Surg 2007;23:203-215

10. Murchison AP, Sires BA, Jian-Amadi A. Margin reflex distance in different ethnic groups. Arch Facial Plast Surg 2009;11:303-305

11. Coombes AG, Sethi CS, Kirkpatrick WN, et al. A standardized digital photography system with computerized eyelid measurement analysis. Plast Reconstr Surg 2007;120:647-656

12. Lam BL, Lam S, Walls RC. Prevalence of palpebral fissure asymmetry in white persons. Am J Ophthalmol 1995;120:518-522

13. Loving RT, Kripke DF, Glazner LK. Circadian rhythms in the human pupil and eyelid. Am J Physiol 1996;271:R320-R324

14. Farkas LG. Accuracy of anthropometric measurements: past, present, and future. Cleft Palate Craniofac J 1996;33:10-18

\section{Do Histopathologic Parameters Affect the Rate of Recurrence in Auricular Keloid Patients?}

\author{
Tae Hwan Park, MD, ${ }^{* \dagger}$ Boram Lee, MD, ${ }^{\ddagger}$ and Ji Hae Park, MD
}

Abstract: The purpose of this study was to describe pathologic features in patients with auricular keloids and estimate its influence on the recurrence of the keloid disease. This study was done in
38 patients reaching the pathologic diagnosis of auricular keloids from March 2012 to February 2014. All patients were female. The average age was $24.06 \pm 5.03(18-47)$ and patients 21 to 23 showed the highest prevalence (38.2\%). The gross morphology of auricular keloids based on our previously introduced classification was pedunculated type (25 patients, 65.8\%) and sessile type (13 patients, $34.2 \%)$.

A detailed case history was taken for every patient with special reference to clinical parameters, such as patient age, gross morphology, and various pathologic parameters, such as margin involvement, keloidal collagen area, perivascular lymphocytic infiltration in upper dermis, perivascular lymphocytic infiltration in keloid, presence of epidermal cyst, presence of foamy histiocytes, foreign body reaction, and superficial dermal involvement. Patient demographics and pathologic characteristics were evaluated as possible risk factors for keloid recurrence. Recurrence was defined as any elevation of the scar or extension beyond the original surgical field.

Of these patients, $86.8 \%$ had successful treatment of their auricular keloids, whereas $13.2 \%$ had recurrences. Based on a current study, there was no significant correlation between the clinicopathologic findings and keloid recurrence.

Key Words: Keloid, pathology, recurrence

\section{PURPOSE}

$\mathrm{K}$ eloids are characterized by excessive wound proliferation beyond the boundaries of their original wounds. Previous literatures have revealed that keloids and hypertrophic scars can be considered as successive stages of the same fibroproliferative skin disorder. ${ }^{1}$ To date, various studies have been conducted to identify the risk factors for keloid recurrence. ${ }^{2}$ To the best of our knowledge, however, there have been no studies to estimate the effect of pathologic parameters on keloid recurrence. Therefore, we conduct a current study to describe pathologic features in patients with auricular keloids and to identify potential relationships between pathologic parameters and keloid recurrence.

\section{METHODS}

\section{Inclusion and Exclusion Criteria}

We reviewed the clinical and histologic features of auricular keloids from the patients who presented to our clinic during a period of 3 years, from March 2012 to February 2014.

The study comprised 38 patients of auricular keloids from among the outpatients of plastic and reconstructive surgery department. The study was approved by the institutional review boards and all subjects gave informed consent before inclusion. All patients were female. The average age was $24.06 \pm 5.03(18-47)$ and patients 21 to 23 showed the highest prevalence (38.2\%). The gross morphology of auricular keloids based on our previously introduced

From the *Buleun Health Care Center, Incheon, Republic of Korea; †Keloid Research Foundation, New York, NY; †Department of Pathology, Samsung Medical Center; and §Department of Plastic and Reconstructive Surgery, Kangbuk Samsung Hospital, Seoul, Republic of Korea.

Received January 12, 2015.

Accepted for publication August 5, 2015

Address correspondence and reprint requests to Tae Hwan Park, MD, Buleun Health Care Center, Gangwha dongro 562-3, Incheon 417-832, Republic of Korea; E-mail: hard-piano@hanmail.net

The authors report no conflicts of interest.

Copyright (C) 2015 by Mutaz B. Habal, MD

ISSN: $1049-2275$

DOI: $10.1097 /$ SCS.0000000000002125 
classification was pedunculated type (25 patients, $65.8 \%$ ) and sessile type (13 patients, $34.2 \%$ ).

Patients with auricular keloids were included in the study according to the following criteria:

(1) The scar was elevated and extended beyond the dimensions of the initiating injury site or lesion, which was confirmed by pathologic findings.

(2) Surgical excision with primary closure was scheduled.

(3) Patients did not undergo additional ear piercings during treatment before final outcome measurement.

Patients were excluded from the study if they were not agreed to perform pathologic study or if they were lost to follow-up.

All keloids were sent out for histologic examination to confirm clinical diagnoses. A detailed case history was taken for every patient with special reference to clinical parameters, such as patient age, bilaterality, and gross morphology.

\section{Pathologic Study}

The excised earlobes were fixed in $10 \%$ buffered formalin, and totally embedded in paraffin blocks after routine preparation process. Then, 7- $\mu \mathrm{m}$ thin sections were subsequently stained using hematoxylin and eosin (H\&E) for usual microscopic examination. We measured pathologic parameters, such as margin involvement, keloidal collagen area $(0 \%-33 \%, 34 \%-66 \%$, and $67 \%-100 \%)$, perivascular lymphocytic infiltration in upper dermis (mild, moderate, and severe), perivascular lymphocytic infiltration in keloid (mild, moderate, and severe), presence of epidermal cyst, presence of foamy histiocytes, presence of foreign body reaction, plasma cell density (PCD), highest area (/HPF), mast cell density (MCD), highest area (/HPF), and superficial dermal involvement $(0 \%-$ $25 \%, 26 \%-50 \%, 51 \%-75 \%$, and $76 \%-100 \%$ ).

\section{Postoperative Outcome Measurement}

Patients were instructed to use a pair of magnets for approximately 12 hours per day for 6 months. Eighteen months postoperatively, patients were seen for evaluation of the success of the therapy (recurrence versus nonrecurrence). Recurrence was defined as any elevation of the scar or extension beyond the original surgical field.

\section{Statistical Analysis}

All statistical analyses were conducted using SPSS version 20.0 (SPSS, Inc., Chicago, IL). Our data were partially normally distributed; consequently have a mixture of nonparametric tests and parametric tests. Descriptive statistics are presented as means with standard deviations/medians with interquartile ranges or as numbers and percentages. To compare medians of continuous variables (eg, patient age), $t$-test was used, whereas Fisher exact tests were used to assess any differences between categorical variables (eg, gross morphology and other pathologic findings). Two-tailed $P$-values $<0.05$ were considered statistically significant.

\section{RESULTS}

Baseline pathologic characteristics are shown in Table 1.

Of these patients, $86.8 \%$ had successful treatment of their auricular keloids, whereas $13.2 \%$ had recurrences. The postoperative course was uneventful without exception. Patient demographics and pathologic characteristics were evaluated as possible risk factors for keloid recurrence. As shown in Table 2, no significant effects on keloid recurrence were noted for patient age and gross morphology and any factors were not significantly associated with events of keloid recurrence.
TABLE 1. Baseline Pathologic Characteristics

Total Patients $(\mathbf{N}=38)$

\begin{tabular}{lc} 
Margin Involvement & \\
No, N (\%) & $13(34.2 \%)$ \\
Yes, N (\%) & $3(7.9 \%)$ \\
Unknown & $22(57.9 \%)$ \\
Keloidal Collagen Area & \\
$0-33$ and N (\%) & $18(47.4 \%)$ \\
$\sim 66 \%$ N (\%) & $11(28.9 \%)$ \\
$\sim 100 \%$, N (\%) & $8(21.1 \%)$ \\
PLI in Upper Dermis & \\
Mild, N (\%) & $13(34.2 \%)$ \\
Moderate, N (\%) & $24(63.2 \%)$ \\
Severe, N (\%) & $1(2.6 \%)$ \\
PLI in Keloid & \\
Mild, N (\%) & $24(63.2 \%)$ \\
Moderate, N (\%) & $9(23.7 \%)$ \\
Severe, N (\%) & $5(13.2 \%)$ \\
Presence of Epidermal Cyst & \\
Absent & $35(92.1 \%)$ \\
Present & $3(7.9 \%)$ \\
Presence of Foamy Histiocytes & \\
Absent & $35(92.1 \%)$ \\
Present & $3(7.9 \%)$ \\
Presence of Foreign Body Reaction & \\
Absent & $37(97.4 \%)$ \\
Present & $1(2.6 \%)$ \\
Superficial Dermal Involvement & \\
$\sim 25 \%$ & $3(7.9 \%)$ \\
$\sim 50 \%$ & $6(15.8 \%)$ \\
$\sim 75 \%$ & $10(26.3 \%)$ \\
$\sim 100 \%$ & $19(50 \%)$ \\
MCD & \\
$\sim 11$ & $23(60.5 \%)$ \\
$\sim 22$ & $13(34.2 \%)$ \\
$23 \sim 33$ & $2(5.3 \%)$ \\
PCD & \\
$\sim 10$ & $29(76.3 \%)$ \\
$\sim 20$ & $8(21.1 \%)$ \\
$21 \sim$ & $1(2.6 \%)$ \\
\hline
\end{tabular}

Values are number (percentages) for categorical variables. MCD, mast cell density, highest area (/HFP); PCD, plasma cell density, highest area (/HFP); PLI, perivascular lymphocytic infiltration.

\section{DISCUSSION}

To date, there have been several studies to distinguish keloids from hypertrophic scars by pathologic features. Lee et $\mathrm{al}^{3}$ suggested that distinguishing keloids from hypertrophic scars pathologically is difficult using 40 keloids and 10 hypertrophic scars. According to their study, alpha-smooth muscle actin (SMA) is not a differentiating marker and presence of several features, such as nonflattened epidermis, nonfibrotic papillary dermis, a tongue-like advancing edge, horizontal cellular fibrous band in the upper reticular dermis, and prominent fascia-like band favors the diagnosis of keloids. Verhaegen and colleagues have attempted to differentiate keloids and hypertrophic scars with reference to collagen orientation and bundle thickness. They found that collagen orientation is not an effective marker to distinguish keloids from hypertrophic scars. Rather, thicker collagen bundles are present in keloidal scar. We think their pathologic diagnosis, however, is based on their own pathologic concept and their diagnosis might be wrong in some extent. This is evidenced by contradictory results of previous 


\begin{tabular}{|c|c|c|c|}
\hline & $\begin{array}{l}\text { Nonrecurrence } \\
\quad(\mathbf{N}=\mathbf{3 3})\end{array}$ & $\begin{array}{l}\text { Recurrence } \\
\quad(\mathbf{N}=5)\end{array}$ & $P$-Value \\
\hline Age & $23.93 \pm 5.264$ & $24.80 \pm 3.768$ & 0.727 \\
\hline \multicolumn{4}{|l|}{ Gross Morphology } \\
\hline Pedunculated type, N (\%) & $23(69.7 \%)$ & $2(40.0 \%)$ & 0.315 \\
\hline Sessile type, N (\%) & $10(30.3 \%)$ & $3(60.0 \%)$ & \\
\hline Margin Involvement & & & 0.160 \\
\hline No, N (\%) & $13(39.4 \%)$ & $0(0.0 \%)$ & \\
\hline Yes, N (\%) & $2(6.1 \%)$ & $1(20.0 \%)$ & \\
\hline Unknown & $18(81.8 \%)$ & $4(18.2 \%)$ & \\
\hline Keloidal Collagen Area & & & 0.604 \\
\hline $0-33$ and $\mathrm{N}(\%)$ & $15(45.4 \%)$ & $4(80.0 \%)$ & \\
\hline$\sim 66 \%, \mathrm{~N}(\%)$ & $10(30.3 \%)$ & $1(20.0 \%)$ & \\
\hline$\sim 100 \%, \mathrm{~N}(\%)$ & $8(24.2 \%)$ & $0(0 \%)$ & \\
\hline PLI in Upper Dermis & & & 1.000 \\
\hline Mild, N (\%) & $11(33.3 \%)$ & $2(40.0 \%)$ & \\
\hline Moderate, N (\%) & $21(63.6 \%)$ & $3(60.0 \%)$ & \\
\hline Severe, N (\%) & $1(30.0 \%)$ & $0(0.0 \%)$ & \\
\hline PLI in Keloid & & & 0.278 \\
\hline Mild, N (\%) & $19(57.6 \%)$ & $5(100 \%)$ & \\
\hline Moderate, N (\%) & $9(27.3 \%)$ & $0(0 \%)$ & \\
\hline Severe, N (\%) & $5(15.2 \%)$ & $0(0 \%)$ & \\
\hline Presence of Epidermal Cyst & & & 1.000 \\
\hline Absent & $30(90.9 \%)$ & $5(100 \%)$ & \\
\hline Present & $3(9.1 \%)$ & $0(0 \%)$ & \\
\hline Presence of Foamy Histiocytes & & & 1.000 \\
\hline Absent & $30(90.9 \%)$ & $5(100 \%)$ & \\
\hline Present & $3(9.1 \%)$ & $0(0 \%)$ & \\
\hline Presence of Foreign Body reaction & & & 1.000 \\
\hline Absent & $32(97.0 \%)$ & $5(100 \%)$ & \\
\hline Present & $1(3.0 \%)$ & $0(0 \%)$ & \\
\hline Superficial Dermal Involvement & & & 0.325 \\
\hline$\sim 25 \%$ & $2(6.1 \%)$ & $1(20.0 \%)$ & \\
\hline$\sim 50 \%$ & $5(15.2 \%)$ & $1(20.0 \%)$ & \\
\hline$\sim 75 \%$ & $10(30.3 \%)$ & $0(0.0 \%)$ & \\
\hline$\sim 100 \%$ & $16(48.5 \%)$ & $3(60.0 \%)$ & \\
\hline MCD & & & 1.000 \\
\hline$\sim 11$ & $20(60.6 \%)$ & $3(60.0 \%)$ & \\
\hline$\sim 22$ & $11(33.3 \%)$ & $2(40.0 \%)$ & \\
\hline $23-33$ & $2(6.1 \%)$ & $0(0 \%)$ & \\
\hline PCD & & & 0.621 \\
\hline$\sim 10$ & $24(72.7 \%)$ & $5(100 \%)$ & \\
\hline$\sim 20$ & $8(24.2 \%)$ & $0(0 \%)$ & \\
\hline $21 \sim$ & $1(3.0 \%)$ & $0(0 \%)$ & \\
\hline
\end{tabular}

Shoulder area is excluded because we do not intend to reach complete remission with our protocol. MCD, mast cell density, highest area (/HFP); PCD, plasma cell density, highest area (/HFP); PLI, perivascular lymphocytic infiltration.

histologic studies. In addition, measuring the thickness of skin collagen bundle is not objective because too much collagen bundles are seen in a single pathologic slide of keloid and its thickness is dependent on the method of sectioning. In a current study, we have found that collagen orientation is not coherent. They are oriented sometimes parallelly or haphazardly. And thickness of collagen bundles is varied in a single slide.

Many researchers have agreed that these 2 entities represent excessive scarring caused by prolonged extracellular matrix accumulation and hence, they are difficult to distinguish both clinically and pathologically. ${ }^{4}$ Clinically, hypertrophic scars spontaneously resolved and keloids would not heal without any interventions. In addition, keloids are known to be resistant to treatment and have high recurrence rates causing serious patient morbidities.
To the best of our knowledge, there have been no studies to find any pathologic parameters that affect keloid recurrence systemically. In this study, we classified pathologic features with several parameters, such as margin involvement, keloidal collagen area, perivascular lymphocytic infiltration in upper dermis, perivascular lymphocytic infiltration in keloid, presence of epidermal cyst, presence of foamy histiocytes, presence of foreign body reaction, PCD, highest area (/HPF), MCD, highest area (/HPF), and superficial dermal involvement. Based on our current study, any pathologic findings do not significantly represent effective parameter to predict keloid recurrence. The only promising finding associated with recurrence was margin involvement even though its $P$-value is not lower than $0.05(P=0.160)$. This finding may need further prospective large-scale studies to ascertain its possible association with keloid recurrence.

Many authors have introduced various postoperative adjuvant therapies for the treatment of auricular keloids. ${ }^{5}$ Because adjuvant radiation therapies involve the risk of possible skin cancers surrounding auricular skin envelope or other malignancies of internal organs, the selection of this therapy is very limited to recalcitrant patients in our cases. The tenuous blood supply is also of concern. Our protocol using surgical excision followed by pressure therapy using magnets, as introduced in our previous study, also yields treatment success with recurrence free rate of $86.8 \%{ }^{6}$ In that study, we characterized 3 potential clinical risk factors for keloid recurrence, with prior treatment history, low growth rates of keloids because of longer duration of disease, and high body mass index.

Our current study sought to build on this previous work by examining pathologic features and identifying pathologic risk factors for keloid recurrence. Our expectation was that evaluation of these pathologic slides would show differences between recurrence and nonrecurrence group.

\section{CONCLUSIONS}

There was no significant correlation between the clinicopathologic findings and keloid recurrence.

\section{REFERENCES}

1. Huang C, Akaishi S, Hyakusoku H, et al. Are keloid and hypertrophic scar different forms of the same disorder? A fibroproliferative skin disorder hypothesis based on keloid findings. Int Wound J 2014;11:517-522

2. Park TH, Chang $\mathrm{CH}$. Location of keloids and its treatment modality may influence the keloid recurrence in children. J Craniofac Surg 2015;26:1355-1357

3. Lee JY, Yang CC, Chao SC, et al. Histopathological differential diagnosis of keloid and hypertrophic scar. Am J Dermatopathol 2004;26:379-384

4. Park TH, Park JH, Chang CH. Challenging the dogma: relationship between time to healing and formation of hypertrophic scars after burn injuries. J Burn Care Res 2014;35:e285-e286

5. Berman B, Viera MH, Amini S, et al. Prevention and management of hypertrophic scars and keloids after burns in children. J Craniofac Surg 2008;19:989-1006

6. Park TH, Seo SW, Kim JK, et al. Outcomes of surgical excision with pressure therapy using magnets and identification of risk factors for recurrent keloids. Plast Reconstr Surg 2011;128:431-439

The Hydraulic Mechanism in the Orbital Blowout Fracture Because of a High-Pressure Air Gun Injury

Seok Joo Kang, MD and Eui Han Chung, MD 
Abstract: There are 2 predominant mechanisms that are used to explain the pathogenesis of orbital blowout fracture; these include hydraulic and buckling mechanisms. Still, however, its pathophysiology remains uncertain. To date, studies in this series have been conducted using dry skulls, cadavers, or animals. But few clinical studies have been conducted to examine whether the hydraulic mechanism is involved in the occurrence of pure orbital blowout fracture.

The authors experienced a case of a 52-year-old man who had a pure medial blowout fracture after sustaining an eye injury because of a high-pressure air gun. Our case suggests that surgeons should be aware of the possibility that the hydraulic mechanism might be involved in the blowout fracture in patients presenting with complications, such as limitation of eye movement, diplopia, and enophthalmos.

Key Words: Blowout fracture, hydraulic, mechanism, pneumocephalus

$\mathrm{O}$ rbital blowout fracture is one of the most common facial traumas that would cause serious functional and aesthetic complications unless diagnosed and treated appropriately. ${ }^{1}$ Its clinical importance and etiology have therefore been studied up to the present.

There are 2 predominant mechanisms that are used to explain the pathogenesis of blowout fracture; these include hydraulic and buckling mechanisms. The former is characterized by the occurrence of blowout fracture because of an abrupt increase in the hydraulic pressure in the orbital contents in the most vulnerable region of the orbit. The latter is characterized by the occurrence of blowout fracture because of the direct impact on the orbital wall. ${ }^{2}$

Clinical symptoms of the blowout fracture have been well documented. Still, however, its pathophysiology remains uncertain. To date, studies in this series have been conducted using dry skulls, cadavers, or animals. But few clinical studies have been conducted to examine whether the hydraulic mechanism is involved in the occurrence of pure blowout fracture.

We experienced a case of a 52-year-old man who had a pure medial blowout fracture after sustaining an eye injury because of a high-pressure air gun. Our patient is consistent with the hydraulic mechanism by which the blowout fracture occurs when the pressure was applied to the globe. Here, we describe our case with a review of literatures.

\section{CLINICAL REPORT}

A 52-year-old man was admitted to our hospital with a chief complaint of a right eye injury because of a high-pressure air gun at work. The patient had edema and ecchymosis in the periorbital region, and complained of eye pain. He also had a limitation of the upward gaze of the right eye. Furthermore, he complained of diplopia and had

From the Department of Plastic and reconstructive Surgery, Busan-Baik Hospital, Inje University School of Medicine, Busan, South Korea.

Received March 15, 2015.

Accepted for publication August 5, 2015

Address correspondence and reprint requests to Seok Joo Kang, MD, Department of Plastic and Reconstructive Surgery, Busan Baik

Hospital, Inje University School of Medicine, 75 Bokji-ro, Busan Jin-gu 614-735, Busan, South Korea; E-mail: sonydr@naver.com

Ethical approval: This study was reviewed and approved by the ethics review board of the InJe University Health Center.

The authors report no conflict of interest.

Copyright (C) 2015 by Mutaz B. Habal, MD

ISSN: 1049-2275

DOI: $10.1097 /$ SCS.0000000000002126 profuse orbital and preseptal emphysema around the right orbit. He had normal light reflex and an intraocular pressure of $12 \mathrm{~mm} \mathrm{Hg}$.

On computed tomography (CT) scans, the patient had blowout fracture in the right lamina papyracea with hemorrhage in the ethmoidal sinus. Moreover, numerous air bubbles were scattered in the subarachnoid space involving basal cisterns and cerebral fissures and sulci (Fig. 1).

The patient achieved a recovery of pneumocephalus at 10 days of the onset of injury. Under general anesthesia, we accessed the orbital wall through a subciliary incision. We confirmed the occurrence of the fracture of the medial orbital wall through an endoscopic surgery. The patient had a fracture of $8 \mathrm{~mm}$ in diameter on the medial wall (Fig. 2). We carefully repositioned the herniated soft tissues around the fracture sites into the orbit and then implanted the absorbable material ResorbX (KLS Martin, Jacksonville, FL) in the fracture sites.

Postoperatively, the patient had normal eye movement without diplopia (Fig. 3). On CT scans, the patient underwent uneventful course.

\section{DISCUSSION}

To date, efforts have been made to clarify the pathophysiologic mechanisms by which orbital fractures. Thus, 2 mechanisms, such as hydraulic and buckling mechanisms, have been proposed to explain them.

Le Fort ${ }^{3}$ was the first to propose the buckling theory, thus suggesting that the thinner orbital floor is vulnerable to the direct force transmitted from the infraorbital rim and this leads to the disruption of the bony structures with fracture of the rim in cases of trauma. On the contrary, Pfeiffer et $\mathrm{al}^{4}$ first proposed the hydraulic theory, according to which there is a transmission of the hydraulic pressure to the orbital wall and this causes a subsequent fracture of the thin orbital floor in patients of the direct trauma to the globe.

It is unlikely that the rim and globe are vulnerable to the isolated trauma in a clinical setting. Moreover, the orbital blowout fracture presents clinical symptoms possibly because of both mechanisms. Of note, our patient showed that the hydraulic mechanism was involved in the occurrence of the blowout fracture, as first proposed by Pfeiffer et al, in that the patient had an eye injury because of a high-pressure air gun.

We believe that there are 3 factors in the blowout fracture related to hydraulic mechanism.

First, hydraulic fracture evidently occurred on the medial wall, as demonstrated by Nagasao et $\mathrm{al}^{5}$ in a simulation experiment using a replica skull. In addition, according to the study by Ahmad et al, ${ }^{6}$ fracture mainly occurs in front of the orbital floor, without fracture in the medial wall, when it occurs via the buckling mechanism. On the contrary, for fractures occurring via the hydraulic mechanism, the extent of the fracture is wider, including the front and back of the orbital floor and the medial wall.

Second, for fractures occurring via the hydraulic mechanism, the fracture is accompanied by clinical symptoms, such as sclera, corneal

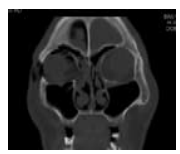

FIGURE 1. Preoperative CT scans. CT, computed tomography.

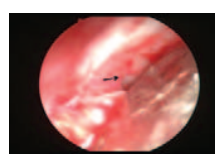

FIGURE 2. Intraoperative findings. An arrow indicates the fracture site. 


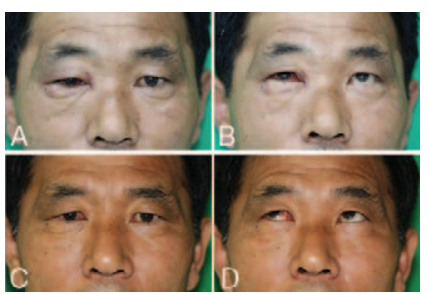

FIGURE 3. A, The patient presented with subconjunctival hemorrhage and proptosis. B, Preoperatively, the patient complained of diplopia accompanied by a limitation of the upward gaze of the right eye. C, On postoperative week 4, the patient had a decrease in the swelling and subconjunctival hemorrhage. D, On postoperative week 4, the patient had no limitation of eye movement and diplopia.

edema, and hematoma. Our patient displayed serious symptoms, such as conjunctival edema, laceration, and chemosis at the time of admission, which were symptoms distinctive from those of other purely isolated medial wall fractures. Nagasao et al ${ }^{5}$ termed symptoms of sclera, corneal edema, and hematoma as "globe symptoms" and mentioned that they are caused by an eye globe-received impact and the effect of the hydraulic mechanism. On the contrary, presence of hematoma, edema of the lower lid, or irregularity of the inferior rim indicates that the buckling mechanism worked. They termed these symptoms as "rim symptoms."

Third, the herniation of the orbital contents might be more prevalent in fractures because of the hydraulic mechanism as compared with those owing to the buckling effect. In our case, we preoperatively observed herniation of the soft tissues around the fracture site on CT scans and then intraoperatively confirmed it. Ahmad et $\mathrm{al}^{6}$ performed an experimental study and reported that the herniation of orbital contents into the maxillary sinus was predominantly seen in fractures because of the hydraulic mechanism but this was not frequently seen in those owing to the buckling one, when the force was exerted to the orbital rim.

In conclusion, our patient is consistent with the blowout fracture because of the hydraulic mechanism. There may be differences in clinical presentations of the orbital blowout fracture between patients' cadavers and replica skulls possibly because of the soft tissues in the eyeball, fat, and muscles as well as the response of the air in the maxillary sinus to trauma. Fractures because of the buckling mechanism are characterized by a higher vulnerability of the soft tissue around the orbit as compared with those due to the hydraulic one. It would therefore be mandatory to identify the actual cause of fractures.

Our case suggests that surgeons should be aware of the possibility that the hydraulic mechanism might be involved in the orbital blowout fracture in patients presenting with complications, such as limitation of eye movement, diplopia, and enophthalmos. Our report on the orbital fracture mechanism is expected to contribute to further studies of blowout fracture mechanisms.

\section{REFERENCES}

1. Kaufman Y, Stal D, Cole P, et al. Orbitozygomatic fracture management. Plast Reconstr Surg 2008;121:1370-1374

2. Erling BF, Iliff N, Robertson B, et al. Footprints of the globe: a practical look at the mechanism of orbital blowout fractures, with a revisit to the work of Raymond Preitter. Plast Reconstr Surg 1999;103:1313-1319

3. Le Fort R. Experimental study of fracture of the upper jaw. In: Tessier P (trans) the classic reprints I and II. Plast Reconstr Surg 1972;50: 497-506600-607

4. Pfeiffer RL. Traumatic enophthalmos. Arch Ophthalmol 1943;30:718-726

5. Nagasao T, Miyamoto J, Jiang H, et al. Interaction of hydraulic and buckling mechanisms in blowout fractures. Ann Plast Surg 2010;64: $471-476$
6. Ahmad F, Kirkpatrick NA, Lyne J, et al. Buckling and hydraulic mechanisms in orbital blowout fractures: fact or fiction? J Craniofac Surg 2006;17:438-441

\section{Treatment of Osteonecrosis of the Jaw}

Eiki Yamachika, DDS, PhD, Masakazu Matsubara, DDS, PhD, Atsushi Ikeda, DDS, Tatsushi Matsumura, DDS, PhD, Norifumi Moritani, DDS, PhD, and Seiji Iida, DDS, PhD

Abstract: The definition of bisphosphonate-related osteonecrosis of the jaw (BRONJ) was recently broadened and it is now known as medication-related osteonecrosis of the jaw (MRONJ). To date, the management of MRONJ is controversial. Conservative treatment is recommended, but it is difficult to successfully treat stage 3 MRONJ. Administration of teriparatide for the MRONJ treatment has only been documented in independent case reports and there are few reports on men with MRONJ treated with teriparatide. An 81year-old man was referred in May 2014 for treatment of an unhealed tooth extraction wound in the mandible. He took minodronic acid hydrate ( $1 \mathrm{mg} / \mathrm{d}$ orally) for 2 years because of osteoporosis cure. On clinical examination, soft tissue swelling in the left mandibular first molar region extended to the inferior border of the mandible with extraoral fistula. Computed tomography (CT) revealed osteolysis extending to the inferior border resulting in pathologic fracture of mandibular bone. Based on these findings, a diagnosis of stage 3 MRONJ was made. We performed conservative treatment, including amoxicillin, but his symptoms did not improve. He was then treated with once-weekly subcutaneous injection of teriparatide. Although teriparatide injections were started without antibiotics, after 1 week, swelling, erythema, and purulent discharge from the extraoral fistula increased rapidly. Therefore, we combined the once-weekly teriparatide injection with amoxicillin administration. Three months later, the osteonecrosis had healed and CT showed significant bone regeneration and healing of the mandibular pathologic fracture. In addition, the mandibular fistula showed healing and the intraoral fistula was covered with normal mucosa.

Key Words: Bisphosphonate, jaws, osteonecrosis, teriparatide

B isphosphonate-related osteonecrosis of the jaw (BRONJ) was first described in 2003 and was subsequently defined as an exposed bone in the oral cavity for 8 weeks in patients who are or were on bisphosphonate (BP) therapy and had not been subjected to radiotherapy in the head and neck region. ${ }^{1,2}$ The American

From the Department of Oral and Maxillofacial Reconstructive Surgery, Okayama University Hospital, Okayama, Japan.

Received May 13, 2015.

Accepted for publication August 5, 2015.

Address correspondence and reprint requests to Eiki Yamachika, Department of Oral and Maxillofacial Reconstructive Surgery, Okayama

University Hospital, 2-5-1, Shikata-cho, Kitaku, Okayama 7008558, Japan; E-mail: eikiyama@md.okayama-u.ac.jp

The authors report no conflicts of interest.

Copyright $\odot 2015$ by Mutaz B. Habal, MD

ISSN: 1049-2275

DOI: $10.1097 /$ SCS.0000000000002127 
Association of Oral and Maxillofacial Surgery (AAOMS) updated their position paper on BRONJ in 2009 and 2014. ${ }^{3,4}$ In the 2014 update, the committee recommended changing the nomenclature of BRONJ to the term medication-related osteonecrosis of the jaw (MRONJ). This new term includes osteonecrosis of the jaw associated with other antiresorptive (denosumab) and antiangiogenic therapies. Patients may be considered to have MRONJ if all the following characteristics are present: current or previous treatment with antiresorptive or antiangiogenic agents; exposed bone or bone that can be probed through an intraoral or extraoral fistula in the maxillofacial region that has persisted for longer than 8 weeks; no history of radiation therapy to the jaws or obvious metastatic disease to the jaws. Therefore, MRONJ is not restricted to exposed bone, and the definition of exposed bone was broadened to include the presence of cutaneous or mucosal fistulas that probe to bone for stage 1,2, and 3 categories.

Stage 3 MRONJ is defined as exposed and necrotic bone or fistula that probes to bone in patients with pain, infection, and at least 1 of the following: exposed and necrotic bone extending beyond the region of alveolar bone resulting in pathologic fracture; extraoral fistula; oral antral or oral nasal communication; or osteolysis extending to the inferior border of the mandible or sinus floor. Management of stage 3 MRONJ is both challenging and controversial. The current consensus is to treat patients conservatively, primarily with antibiotics, analgesics, mouth irrigation, maintenance of good oral hygiene, and superficial debridement. These patients, however, typically require removal of sequestra, including jaw bone resection, in combination with antibiotic therapy. Thus, symptomatic patients with stage 3 may require resection and immediate reconstruction, and this may complicate the problem. Thus, improvement of conservative therapy and/or development of new therapies is required.

Parathyroid hormone $(\mathrm{PTH})$ is the major hormone that regulates bone remodeling. Although continuous infusion of high doses of PTH has catabolic effects, intermittent administration of PTH at low doses is anabolic for bone formation. Teriparatide [recombinant human PTH-(1-34)] is an anabolic agent shown to increase both bone mass and bone strength. ${ }^{5}$ It has been shown to be effective in the treatment of osteoporosis in postmenopausal populations and is currently an accepted treatment of severe osteoporosis. It has not been widely used in the treatment of MRONJ (BRONJ); however, there have been some reports of teriparatide in the treatment of MRONJ (BRONJ). Administration of teriparatide for the resolution of BRONJ was first described by Harper and Fung ${ }^{6}$ in 2007. Subsequently, the administration of teriparatide has been documented in independent case reports. In these reports, MRONJ (BRONJ) is much more commonly reported in women, and there have been few reports on male MRONJ (BRONJ) patients treated with teriparatide.

We report here a man with stage 3 MRONJ who was successfully treated with 3 months of once-weekly teriparatide injections and administration of amoxicillin.

\section{CLINICAL REPORT}

An 81-year-old man was referred in May 2014 for treatment of an unhealed tooth extraction wound in the mandible. He took minodronic acid hydrate ( $1 \mathrm{mg} / \mathrm{d}$ orally) for 2 years because of osteoporosis cure. He had undergone extraction of the left mandibular first molar 5 months earlier. One month after tooth extraction, painful mucosal swelling and intraoral fistula developed in that region. The symptoms did not improve following conservative treatment, including oral amoxicillin hydrate administration $(750 \mathrm{mg} / \mathrm{d})$ and oral irrigation with aqueous iodine solution at other hospitals. On clinical examination, he had infection of both the soft tissue and bone. Intraoral fistula was recognized at the left mandibular first molar region and the soft tissue swelling extended to

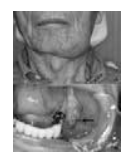

FIGURE 1. A, Initial appearance showing soft tissue swelling and erythema extending to the inferior border of the mandible. B, Intraoral aspect, showing fistula and purulent discharge at the left mandibular first molar region.

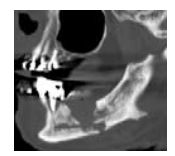

FIGURE 2. Sagittal computed tomography scan showing persistent unhealed extraction socket in the region of the left inferior first molar and revealing a hypodense area, drilling cortical bone, and resulting in pathologic fracture of mandibular bone.

inferior border of the mandible (Fig. 1A-B). Computed tomography revealed osteolysis extending to the inferior border resulting in pathologic fracture of the mandibular bone (Fig. 2). He did not have any other medication or systemic diseases. Biopsy of the soft tissue swelling was performed, and the results showed chronic inflammation. He had no history of cancer or previous irradiation to the head and neck region. Based on medical history and both clinical and radiographic findings, a diagnosis of stage 3 MRONJ was made according to AAOMS guidelines (2014). ${ }^{4}$

We administered conservative treatment, including instruction on oral hygiene, oral amoxicillin hydrate administration $(750 \mathrm{mg} / \mathrm{d})$, and oral irrigation, with only a temporary reduction of inflammation and purulent discharge. Therefore, we planned to treat him with teriparatide by once-weekly subcutaneous injection $(56.5 \mu \mathrm{g}$ weekly). Initially, theriparatide therapy was started without oral amoxicillin hydrate administration, but 1 week after amoxicillin was finished, swelling, erythema, and purulent discharge from the extraoral fistula increased rapidly (Fig. 3). The biopsy report from this region confirmed abscess and focal inflammation. We believed that inflammation was reactivated because antibiotic therapy was stopped. Thus, we combined the teriparatide treatment with amoxicillin hydrate administration $(750 \mathrm{mg} / \mathrm{d})$ and continued this combination therapy for 3 months. After 3 months, his symptoms had resolved and the osteonecrosis had healed. Computed tomography showed significant bone regeneration and healing of the mandibular pathologic fracture (Fig. 4), and the mandibular extraoral and intraoral fistula was covered by normal skin and mucosa, respectively. Administration of teriparatide and amoxicillin was stopped at this time, and no signs of inflammation, including swelling, erythema, and fistula, were observed.

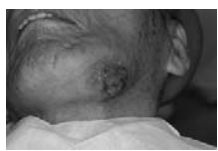

FIGURE 3. Extraoral fistula at the inferior border of left mandible showing purulent discharge, swelling, and erythema.

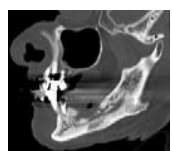

FIGURE 4. Sagittal computed tomography scan revealing significant bone regeneration and healing of the mandibular pathologic fracture. 


\section{DISCUSSION}

Teriparatide therapy in osteoporotic patients increases mechanical bone strength without impairing osteoclast function and reduces the risk for bone fractures. ${ }^{5,7,8}$ Moreover, it has been reported that teriparatide has an effect on fracture healing. ${ }^{9}$ In view of its anabolic effect to bone, teriparatide may be beneficial for MRONJ, as it provides bone regeneration against pathologic fracture. To allow bone regeneration for MRONJ, infection must be controlled, and bone metabolism should be improved. Therefore, established conservative therapy would not be effective enough for MRONJ patients. In addition, teriparatide is usually given by daily injection; however, this is problematic for elderly patients; thus, once-weekly use of teriparatide has advantage to daily use, if the effects are the same. The effects of once-weekly teriparatide therapy to BRONJ have been reported. ${ }^{10}$ However, their report focused only on female BRONJ patients and the necessity of antibiotic combination therapy was not mentioned.

In this report, we confirmed that once-weekly teriparatide was effective in a man with stage 3 MRONJ, and demonstrated the necessity of combination antibiotic therapy. Teriparatide has no anti-inflammatory effects, and it is therefore reasonable to combine it with antibiotic therapy.

Our experience with this patient prompted us to propose a new treatment regimen pairing teriparatide with amoxicillin, and suggest that it is highly effective in MRONJ.

In conclusion, the outcome in this patient suggests that 3 months once-weekly teriparatide therapy combined with administration of amoxicillin is effective against MRONJ.

\section{REFERENCES}

1. Marx RE. Pamidronate (Aredia) and zoledronate (Zometa) induced avascular necrosis of the jaws: a growing epidemic. J Oral Maxillofac Surg 2003;61:1115-1117

2. American Association of Oral and Maxillofacial Surgeons position paper on bisphosphonate-related osteonecrosis of the jaws. J Oral Maxillofac Surg 2007;65:369-376

3. Ruggiero SL, Dodson TB, Assael LA, et al. American Association of Oral and Maxillofacial Surgeons position paper on bisphosphonaterelated osteonecrosis of the jaw-2009 update. Aust Endod J 2009;35:119-130

4. Ruggiero SL, Dodson TB, Fantasia J, et al. American Association of Oral and Maxillofacial Surgeons position paper on medication-related osteonecrosis of the jaw-2014 update. J Oral Maxillofac Surg 2014;72:1938-1956

5. Neer RM, Arnaud CD, Zanchetta JR, et al. Effect of parathyroid hormone (1-34) on fractures and bone mineral density in postmenopausal women with osteoporosis. N Engl J Med 2001;344: 1434-1441

6. Harper RP, Fung E. Resolution of bisphosphonate-associated osteonecrosis of the mandible: possible application for intermittent lowdose parathyroid hormone [rhPTH(1-34)]. J Oral Maxillofac Surg 2007;65:573-580

7. Dempster DW, Cosman F, Kurland ES, et al. Effects of daily treatment with parathyroid hormone on bone microarchitecture and turnover in patients with osteoporosis: a paired biopsy study. J Bone Miner Res 2001;16:1846-1853

8. Hodsman AB, Bauer DC, Dempster DW, et al. Parathyroid hormone and teriparatide for the treatment of osteoporosis: a review of the evidence and suggested guidelines for its use. Endocr Rev 2005;26:688703

9. Aspenberg P, Johansson T. Teriparatide improves early callus formation in distal radial fractures. Acta Orthop 2010;81:234-236

10. Yoshiga D, Yamashita Y, Nakamichi I, et al. Weekly teriparatide injections successfully treated advanced bisphosphonaterelated osteonecrosis of the jaws. Osteoporos Int 2013;24:23652369

\section{Surgery Approaches to Brainstem Cavernous Malformations}

\author{
Zhen Wang, MD, Chunhua Qian, MD, Lufeng Shi, MD, \\ Lin Wang, MD, Jianmin Zhang, MD, and Yongjie Wang, MD
}

Background and Purpose: To summarize our experience in surgery approach to brainstem cavernous malformation (BSCM). Methods: A review of 23 consecutive patients with BSCM receiving surgical resection in our center between July of 2003 and June of 2014 was performed.

Results: Suboccipital approach, retrosigmoid approach, infratentorial-supracerebellar approach, Poppen approach, pterional approach, Kawase approach, and interhemispheric transcallosalthird ventrical approach were applied, of which the last 2 approaches being firstly reported in BSCM surgery. Gross total resection was achieved in 22 patients, whereas subtotal resection in 1. Neurologic function was improved in 15 patients, unchanged in 7 patients, and deteriorated in 1 patient. During a mean follow-up of 3.5 years, no recurrence occurred.

Conclusions: Proper surgery approach is important to assure total resection, protect normal vital structures, and avoid recurrence.

Key Words: Brainstem cavernous malformation, interhemispheric transcallosal-third ventrical approach, Kawase approach, surgery approaches

avernous malformations (CMs) are made up of thin-walled, grossly dilated blood vessels lined with endothelium. It made up of $5 \%$ to $13 \%$ of all the vascular diseases in the central nervous system. ${ }^{1,2}$ As a special subtype, brain stem CMs (BSCMs) account for $9 \%$ to $35 \%$ of the intracranial CMs, and occur most commonly in pons, followed by midbrain, but rarely in medulla, often in accompany with venous malformations. ${ }^{3}$ Brainstem cavernous malformations often cause hemorrhage and lead to acute focal neurologic deficits. It is estimated that the hemorrhage rates of BSCMs range from $2.33 \%$ to $10.6 \%$ per patient-year, and the rehemorrahge rates after first strike are elevated to $5 \%$ to $21.5 \%{ }^{4}$ Although the symptoms tend to resolve spontaneously, some patients suffer from devastating neurologic complications. ${ }^{3}$ Surgical resection is

From the Department of Neurosurgery, 2nd Affiliated Hospital, School of Medicine, Zhejiang University, Hangzhou, Zhejiang, People's Republic of China.

Received May 26, 2015.

Accepted for publication August 7, 2015.

Address correspondence and reprint requests to Yongjie Wang, MD, Department of Neurosurgery, 2nd Affiliated Hospital, School of Medicine, Zhejiang University, 88\# Jiefang Road, 310009 Hangzhou, Zhejiang, People's Republic of China; E-mail: 11018196@zju.edu.cn

Zhen Wang and Chunhua Qian contributed equally to this work and should be considered as co-authors.

Funding: The work has been funded by Zhejiang Provincial Department of Health Project (Y136222013).

The authors report no conflicts of interest.

Copyright $(1) 2015$ by Mutaz B. Habal, MD

ISSN: 1049-2275

DOI: $10.1097 /$ SCS.0000000000002128 
indicated for the patients with repetitive hemorrhage and deteriorating neurologic deficits. Owing to the deep-seated position, complicated structure and important function of the brain stem, the surgery carries high-risk and proper selection of surgery approaches - is key to assure total lesion resection, protect normal brain tissue, and prevent severe postsurgical complications. Therefore, a retrospective study of the BSCMs receiving microsurgical resection in our center between July 2003 and June 2014 was performed, together with the illustration of 2 approaches firstly applied in the BSCMs, highlighting surgery approach selection.

\section{METHODS}

The ethics committees of 2nd Affiliated Hospital, Zhejiang University, School of Medicine approved this study. Written informed consents were obtained from patients. The data were analyzed anonymously. Consecutive BSCM cases admitted in our department from July 2003 to June 2014 were collected and reviewed. All patients with preoperational magnetic resonance imaging (MRI) study, histology confirming the diagnosis of CM, and postoperational follow-ups were eligible for the study.

Surgery was indicated for patients presenting with neurologic deficits and the lesions bringing to the surface of the brain stem. The surgery approaches were selected by locating the cortex surface proximal to the lesion and to avoid destructing important surrounding structures, with the help of electrophysiologic monitoring and intraoperative neuronavigation. In our series, suboccipital approach, retrosigmoid approach, infratentorial-supracerebellar approach, Poppen approach, pterional approach, Kawase approach, and interhemispheric transcallosal-third ventrical approach were applied, the last 2 being firstly reported in the treatment of BSCM. The CMs were separated around the hematoma to achieve total resection, which was an important step to prevent recurrence. Low voltage bipolar was applied for hemostasis to reduce heat conductivity.

Follow-up was scheduled immediately after surgery, 3 months and 6 months after discharge, and yearly afterwards. The MRI was used for evaluation. The physical examination was also performed to assess the neurologic status.

\section{RESULTS}

\section{Patient Characteristics}

There were totally 23 patients, including 13 men and 10 women, with a mean age of 41 years (15-62 years old). The clinical manifestations were categorized into 4 groups: 9 patients suffered from symptoms related to intracranial hypertension, such as headache, nausea, and vomiting; 12 complained of cranial nerve deficits, such as aphasia and dysphagia; 9 displayed conductive tracts dysfunction, such as numbness and muscle weakness; 7 presented with cerebellar signs, such as dizziness and ataxia. The MRI confirmed 16 lesions mainly located at pons, 5 at midbrain, and 2 at medulla. Altogether, there were 5 patients with apparent venous malformations.

\section{Surgical Approches}

Suboccipital approach was applied in 5 patients, whereas retrosigmoid approach in 6, infratentorial-supracerebellar approach in 4, Poppen approach in 3, pterional approach in 3, Kawase approach in 1 , and interhemispheric transcallosal-third ventrical approach in 1. The characteristic MRI of each approach was displayed in Figure 1. All surgeries were well performed with no severe intraoperative complication.

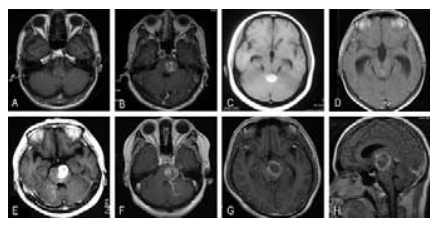

FIGURE 1. Characteristic magnetic resonance imaging findings and corresponding surgery approaches: A, Cavernous malformations in the dorsal medulla oblongata, operated via suboccipital approach. B, Cavernous malformations in the ventrolateral pons, operated via retrosigmoid approach. C, Cavernous malformations in the dorsal midbrain, operated via infratentorialsupracerebellar approach. D, Cavernous malformations in the dorsal midbrain, operated via Poppen approach. E, Cavernous malformations in the ventrolateral midbrain, operated via pterional approach. F, Cavernous malformations in the ventrolateral pons, operated via Kawase approach. $\mathrm{G}$ and $\mathrm{H}$, Cavernous malformations in the tectum mesencephali, operated via interhemispheric transcallosal-third ventrical approach.

\section{Outcome}

The postoperative course was uneventful. Postoperative MRI revealed gross total resection in 22 patients and subtotal resection in 1. Neurologic function was improved in 15 patients, unchanged in 7 , and deteriorated in 1. Postoperative complications, such as rehemorrhage, hydrocephalus, infection, venous thrombus, cerebrospinal fluid leakage, seizure, conscious disturbance, respiratory failure, cardiac arrhythmia, etc., did not occur. During a mean follow-up period of 3.5 years ( 3 months to 8 years), all the patients recovered well and were life-independent without recurrence.

\section{Patient 1}

The patient was a 43-year-old woman, presented with weakness of right extremities and dysarthria for 1 month. Preoperative MRI demonstrated a high intensity mass of the left ventrolateral pons and venous malformation of the left cerebellar hemisphere (Fig. 1F). We resected the lesion from an anterolateral direction via Kawase approach. After craniotomy, an extradural subtemporal path was followed to the petrosal ridge and the petrosal apex was drilled. Then dura was opened, temporal lobe was elevated, and tentorium was incised to reach the pons. The surface area with hemosiderin deposition was easily visualized and a $0.5 \mathrm{~cm}$ incision was made at the suprafacial triangle of the brainstem. Total resection was performed by dissecting along the capsule of the lesion (Fig. 1D). Postoperative MRI demonstrated complete resection. The patient recovered well.

\section{Patient 2}

The patient was a 23-year-old man, presented with dizziness and blurred vision for 1 month. Preoperative MRI demonstrated a circular high intensity lesion in the left midbrain and thalamus (Fig. 1G-H). Interhemispheric transcallosal-third ventrical approach was applied. Corpus callosum was exposed through the interhemispheric fissure and was dissected as an entry into the third ventricle. The yellowish lesion was located at the left posteriolateral wall of the third ventricle. Decompression was achieved by incising into the hematoma. The CM was dissected along the capsule and total resection was achieved, confirmed by the postoperative MRI. The patient recovered well except a dilated left pupil as before the operation.

\section{DISCUSSION}

Most untreated BSCMs were self-limited and would resolve over time. ${ }^{5,6}$ Considering the complex anatomy of the brain stem and the high surgical risks, surgery is only reserved for patients who meet the following criteria: the lesion reaches the pial surface; progressive neurologic deficits caused by repetitive hemorrhages; 


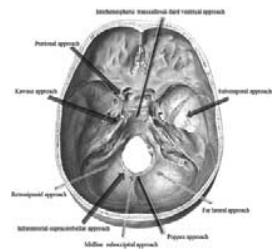

FIGURE 2. Illustration of surgery approaches for brainstem cavernous malformations.

extracapsular acute hemorrhage; significant space-occupying effect because of lesion larger than $2 \mathrm{~cm}$; symptomatic CM with a satellite subacute hematoma. ${ }^{5-7}$ It is recommended to perform the surgery at the subacute stage when the hematoma turns liquefied and a clear boundary is formed. Otherwise in the acute phase, the brain edema is significant, or in the chronic phase, the fabrication and organization of the hematoma will exaggerate the adhesion to the normal surroundings, which carries higher risk of intraoperative damage and subtotal resection. ${ }^{8}$

Choosing the appropriate surgery approach is critical to minimize the injury, reduce the risk of postoperative complications, and better visualization. As displayed in Figure 2, various approaches are available and should be selected according to the CM's exact location at brain stem. ${ }^{9}$ The midline suboccipital approach is used to expose the floor or lateral walls of the fourth ventricle for $\mathrm{CMs}$ dorsal to the pons and medulla; ${ }^{10}$ whereas the retrosigmoid approach makes the use of the angle between tentorial and posterior petrous bone, especially suitable for CMs ventral and ventrolateral to the pons ${ }^{10}$ the infratentorial-supracerebellar approach consist of middle, paramedian, and extreme lateral variants, allowing safe circumferential exposure of CMs within the posterior and middle incisural space areas; ${ }^{11}$ whereas Poppen approach reaches quadrigeminal cistern superiorly by cutting through the tentorial and is appropriate for CMs straddling the tentorial; ${ }^{11}$ the far lateral approach targets the inferior medulla and superior cervical spine from the sideway and thereafter suitable for ventrolateral medullary $\mathrm{CMs} ;{ }^{12}$ pterional approach accesses the anterior midbrain, but is limited for lesions spreading toward the pons. The problems could be perfectly solved by orbitozygomatic approach, which provides wide access to the midbrain-pons junction. ${ }^{13}$

In addition, our center firstly reported the application of 2 new approaches in the resection of BSCMs. The subtemporal-anterior transpetrous approach, also known as Kawase approach, was designed to clip lower basilar trunk aneurysms facing toward the brainstem. ${ }^{14}$ Extradural subtemporal access to the petrosal ridge and drilling of the Kawase angle circled by superior petrous sinus, great petrous nerve, and trigeminal nerve, produce a route to observe lesions located ventrolateral to pons, with minimal injury to the temporal lobe, sigmoid sinus, Labbe vein, and nerves. ${ }^{14,15}$ Various modified Kawase approaches are used to resect lesions surrounding petroclival region, such as meningioma, chordoma, epidermoid cyst, etc. ${ }^{16,17}$ We firstly used Kawase approach to resect a BSCM in the ventral pons with a posterolaterally located venous malformation. Considering the possibility of injuring the venous malformation during exposure via suboccipital retrosigmoid approach, the Kawase approach was performed. The gross total resection was achieved and the patient recovered well without permanent neurologic sequela.

Interhemispheric transcallosal-third ventrical approach consisted of a median longitudinal incision through the anterior third of the callosum, extended for a maximal distance of 2.5 to $3 \mathrm{~cm}$, paralleling the major axis of the callosum. The sagittal callosotomy takes place as a relatively safe procedure to access third ventricle. The approach is mostly used for lesions locating in the third or lateral ventricles, thalamus, and sella or pineal region protruding into the ventricles. ${ }^{18,19}$ Our center firstly applied this approach in $\mathrm{CM}$ of the tectum mesencephali. Although the exposure is complicated and time-consuming, this approach provide the surgeon with a directly view of large $\mathrm{CM}$ at the roof of midbrain through the posterior third ventricle. In this case, the gross total resection was successfully achieved with no postoperational complications.

\section{CONCLUSIONS}

Owing to the deep location and important neighboring structures, the resection of BSCMs is challenging and risky. There exists a bundle of surgery approaches, each approaching the brain stem from different planes and angles. According to our experience, Kawase approach and interhemispheric transcallosal-third ventrical approach can achieve good outcome in selected cases. Even in experienced hands, individualized selection of right surgery approach is of vital importance. Together with microsurgical techniques, neuronavigation, and nervous monitoring, it is possible to achieve total resection, protect normal vital structures, and avoid postoperative recurrence.

\section{REFERENCES}

1. Simard JM, Garcia-Bengochea F, Ballinger WE Jr et al. Cavernous angioma: a review of 126 collected and 12 new clinical cases. Neurosurgery 1986;18:162-172

2. Tekkok IH, Ventureyra EC. De novo familial cavernous malformation presenting with hemorrhage 12.5 years after the initial hemorrhagic Ictus: natural history of an infantile form. Pediatr Neurosurg 1996;25:151-155

3. Fritschi JA, Reulen HJ, Spetzler RF, et al. Cavernous malformations of the brain stem. A review of 139 cases. Acta Neurochir (Wien) 1994;130:35-46

4. Gross BA, Batjer HH, Awad IA, et al. Brainstem cavernous malformations. Neurosurgery 2009;64:E805-E818discussion E818

5. Li D, Hao SY, Jia GJ, et al. Hemorrhage risks and functional outcomes of untreated brainstem cavernous malformations. J Neurosurg 2014;121:32-41

6. Li D, Hao SY, Tang J, et al. Clinical course of untreated pediatric brainstem cavernous malformations: hemorrhage risk and functional recovery. J Neurosurg Pediatr 2014;13:471-483

7. Li D, Yang Y, Hao SY, et al. Hemorrhage risk, surgical management, and functional outcome of brainstem cavernous malformations. J Neurosurg 2013;119:996-1008

8. Bradac O, Majovsky M, de Lacy P, et al. Surgery of brainstem cavernous malformations. Acta Neurochir (Wien) 2013;155:2079-2083

9. Giliberto G, Lanzino DJ, Diehn FE, et al. Brainstem cavernous malformations: anatomical, clinical, and surgical considerations. Neurosurg Focus 2010;29:E9

10. Ohue S, Fukushima T, Kumon Y, et al. Surgical management of brainstem cavernomas: selection of approaches and microsurgical techniques. Neurosurg Rev 2010;33:315-322discussion 323-314

11. Ammirati M, Bernardo A, Musumeci A, et al. Comparison of different infratentorial-supracerebellar approaches to the posterior and middle incisural space: a cadaveric study. J Neurosurg 2002;97:922-928

12. Garber ST, Couldwell WT. Resection of an inferior pontine cavernous malformation using a far-lateral transcondylar approach. Acta Neurochir (Wien) 2011;153:2461-2464

13. Zabramski JM, Kiris T, Sankhla SK, et al. Orbitozygomatic craniotomy. Technical note. J Neurosurg 1998;89:336-341

14. Kawase T, Toya S, Shiobara R, et al. Transpetrosal approach for aneurysms of the lower basilar artery. J Neurosurg 1985;63:857-861

15. Aziz KM, van Loveren HR, Tew JM Jr et al. The Kawase approach to retrosellar and upper clival basilar aneurysms. Neurosurgery 1999;44:1225-1234discussion 1234-1226

16. Kawase T, Shiobara R, Toya S. Anterior transpetrosal-transtentorial approach for sphenopetroclival meningiomas: surgical method and results in 10 patients. Neurosurgery 1991;28:869-875discussion 875866 
17. Shimamoto Y, Kawase T, Sasaki H, et al. Anterior transpetrosal approach to the prepontine epidermoids. Skull Base Surg 1999;9:75-80

18. Easwer HV, Bhattacharya RN, Nair S, et al. Pre-coronal, paramedian minicraniotomy: a minimal access approach for microsurgical, transcallosal, transforaminal removal of colloid cysts of the third ventricle. Minim Invasive Neurosurg 2008;51:253-257

19. Mazza M, Di Rienzo A, Costagliola C, et al. The interhemispheric transcallosal-transversal approach to the lesions of the anterior and middle third ventricle: surgical validity and neuropsychological evaluation of the outcome. Brain Cogn 2004;55:525-534

\section{The Presence of Clival Foramen Through Multidetector Computed Tomography of the Skull Base}

Mikail Inal, MD, ${ }^{*}$ Nuray Bayar Muluk, $M D^{\dagger}$ Mehmet Faik Ozveren, MD, ${ }^{\ddagger}$ Umut Orkun Çelebi, MD, ${ }^{\S}$ Gökçe Şimşek, MD," Veysel Burulday, MD, ${ }^{*}$ and Mihrace Yasemin Karadeniz Bilgili, MD

Objectives: Technological advancements in the diagnostic radiology recently permitted reviewing the normal anatomy through multidetector computed tomography (MDCT) imagination. The aim of this paper is retrospectively investigation of the clival foramen and canal through MDCT.

Materials and Methods: One hundred eighty-six MDCT scans were reviewed. First, images were taken at axial plane, and then coronal and sagittal reconstructions of raw data were performed. Later investigations were carried out on these three-dimensional images (3-D imaging). The images were evaluated as clival foramen "present" or "absent."

Results: In our 186 patients, evaluation of MDCT showed that clival foramen was absent in $66.7 \%(n=124)$ of patients. Only $33.3 \%(n=62)$ of patients had a clival foramen. In 3-D images, clival canal and clival foramen were shown more clearly compared with the MDCT.

Conclusions: Knowledge of the clival canal might be useful in patients of questionable clival fracture or during neurosurgical operations in this region. During life the canal contained a vein connecting the basilar plexus with the venous plexus of the vertebral canal, and inferior petrosal sinuses. Before the surgical interventions in the clival region, the presence of the clival canal and foramen should also be known due to its vascular contents. By

From the *Department of Radiodiagnostics; †Department of Otolaryngology; ‡Department of Neurosurgery; §Department of Radiodiagnostics; \|Department of Otolaryngology; and Department of Radiodiagnostics, School of Medicine, Kirikkale University, Kirikkale, Turkey.

Received April 9, 2015.

Accepted for publication August 7, 2015.

Address correspondence and reprint requests to Dr Nuray Bayar Muluk, Birlik Mahallesi, Zirvekent 2. Etap Sitesi, C-3 blok, No: 62/43, 06610 Cankaya,

Ankara, Turkey; E-mail: nbayarmuluk@yahoo.com,nurayb@hotmail.com The authors report no conflicts of interest.

Supplemental digital contents are available for this article. Direct URL citations appear in the printed text and are provided in the HTML and PDF versions of this article on the journal's Web site (www.jcraniofa cialsurgery.com).

Copyright (C) 2015 by Mutaz B. Habal, MD

ISSN: 1049-2275

DOI: $10.1097 /$ SCS.0000000000002129 multidetector computed tomography and 3-D images, clival canal and foramen may be viewed preoperatively.

Key Words: Three-dimensional images, clival canal, clival foramen, multidetector computed tomography (MDCT)

$\mathrm{T}$ he chordal chondrocranium is composed of parachondral cartilages that form by fusion of the base of the skull in the 3rd fetal month. ${ }^{1}$ During the combination of these parachondral cartilages, sinus petrosus inferior is surrounded by these ossifying elements from both sides. As a result of this process, some of the vessels forming the sinus form a channel of their own by staying in these bones. This canal, in which these vessels located, is called clival canal. Clivus is the growing part between basiocciput and basisphenoid parts. Clival channel is usually in the one-third central part of the clivus. ${ }^{2,3}$

Nayak et $\mathrm{al}^{2}$ reported that the clival canal was located in the middle third of the clivus, the fused portion of basiocciput and basisphenoid, which constitute clivus. The canal might be the remnant of the first true sclerotome, which has not disappeared during course of development. A shallow fossa is occasionally found on the ventral surface of the basilar portion anterior to the pharyngeal tubercle, which has been interpreted as a vestige of the canal of the notochord. ${ }^{4}$

Technological advancements in the diagnostic radiology recently permitted reviewing the normal anatomy through multidetector computed tomography (MDCT) imagination. ${ }^{5}$ As there are not many studies focused on the presence of clival foramen and canal by using MDCT, the aim of this paper is retrospectively investigation of its percentage in a series of humans and to point out its significance in clinical medicine. We also presented three-dimensional images of the clival foramen and canal. To our knowledge, this is the first study in the literature made with computed tomography.

\section{METHODS}

This retrospective study was conducted in Radiodiagnosics Department of Kirikkale University Faculty of Medicine between November 2013 and December 2014. Ethics Committee Approval was also taken from Kirikkale University Faculty of Medicine Ethics Committee. Computed tomography scans of the subjects which were performed in the Radiodiagnostics Department of Kirikkale University Faculty of Medicine Radiodiagnostics Department were evaluated retrospectively.

\section{Subjects}

One hundred eighty-six computed tomography scans were reviewed. Mean age of the patients was $38 \pm 16$. In total, $51.1 \%$ $(n=95)$ of patients were male and remaining $48.9 \%(n=91)$ of patients were female.

Subjects with previous trauma or surgery history, cranial tumor, known neurological diseases, and marked cranial or facial deformity were not included in the study.

This study is retrospective. Ethics committee approval was obtained. There is no need to take informed consent, because the data were evaluated retrospectively.

\section{Multidetector Computed Tomography}

All the scans were obtained from routine temporal bone imaginations in supin position, and no contrast and sedation were used for the procedure. The images were acquired with a 64-slice CT (MSCT, Philips Medical System, Brillance 64, Best, The Netherlands). All the scans were obtained using the following parameters: tube voltage, $120 \mathrm{kV}$; effective mAs, 350; slice thickness, $0.67 \mathrm{~mm}$; the scan field of 
view of $180 \mathrm{~mm}$, and image matrix of $768 \times 768$ were used. All images were transferred to a commercially available workstation. First images were taken at axial plane, and then coronal and sagittal reconstructions of raw data were performed. Later investigations were carried out on these three-dimensional images (3-D imaging).

In the axial, coronal, and sagittal multislice computed tomography views, and on the three-dimensional images, clivus was evaluated, and the patients with clival foramen were detected.

\section{Statistical Analysis}

All analyses were performed using version 16 of the Statistical Package for the Social Sciences software. $\chi^{2}$ test and Spearman's correlation rho efficient test were used.

A $P$ value $<0.05$ was considered to reflect statistical significance.

\section{RESULTS}

In axial and sagittal sections (Fig. 1), clival canal and clival foramen were shown in multidetector computed tomography. In the 3-D images (see Supplemental Digital Content, Figure 2, http:// links.lww.com/SCS/A167), clival canal and clival foramen were shown on clivus. Also in the oblique view of 3-D images, clival canal and clival foramen were shown (see Supplemental Digital Content, Figure 3, http://links.lww.com/SCS/A168).

It was obvious that, in 3-D images, clival canal and clival foramen were shown more clearly compared with the MDCT.

In our 186 patients, evaluation of MDCT showed that clival foramen was absent in $66.7 \%(n=124)$ of patients. Only $33.3 \%$ $(\mathrm{n}=62)$ of patients had a clival foramen.

Sex distribution is shown in Table 1. In the male group, clival foramen was detected in $37.9 \%$ of the patients, and in the female group, clival foramen was detected in $28.6 \%$ of the patients. There was no significant difference between the clival foramen presence values of the males and females $(P>0.05)$.

There was no significant correlation between age, sex, and the presence of clival foramen by Spearman's correlation rho efficient test $(P>0.05)$.

\section{DISCUSSION}

Development of clivus is completed at 11 years of life with final width and length. ${ }^{6}$ The clival canal was longitudinally placed

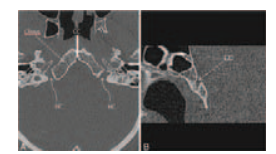

FIGURE 1. Clival canal and clival foramen were shown in multidetector computed tomography (CC, clival canal; HC, hypoglossal canal). A, Axial sections; $B$, sagittal sections.

TABLE 1. Gender Distribution

\begin{tabular}{|c|c|c|c|c|c|}
\hline \multirow[b]{3}{*}{ Gender } & \multicolumn{4}{|c|}{ Clival Foramen } & \multirow[b]{3}{*}{$P^{*}$} \\
\hline & \multicolumn{2}{|c|}{ Present } & \multicolumn{2}{|c|}{ Absent } & \\
\hline & $\mathbf{n}$ & $\%$ & $\mathbf{n}$ & $\%$ & \\
\hline Male $(\mathrm{n}=95)$ & 36 & 37.9 & 59 & 62.1 & $P=0.178 \quad \chi^{2}=1.818$ \\
\hline Female $(\mathrm{n}=91)$ & 26 & 28.6 & 65 & 71.4 & \\
\hline
\end{tabular}

${ }^{*} P$ value shows the results of $\chi^{2}$ test. in the clivus and the width of the canal was $1.2 \mathrm{~mm}$. The boundary of the head and neck corresponds to the boundary between the fifth and sixth somites. The first true somite disappears early and somites 2-5 (occipital 1-4) fuse to form the basioccipital bone. ${ }^{7}$ The opening of the clival canal onto the clivus is known as clival foramen.

Jalsovec and Vinter ${ }^{1}$ reported that they could only speculate about the contents and significance of the clival canal. Taking into consideration the localization of the canal, they considered 2 possible explanations. First, during life the canal contained a vein connecting the basilar plexus with the venous plexus of the vertebral canal; ${ }^{1}$ and inferior petrosal sinuses. ${ }^{2}$ Second, the canal contained remnants of the notochord. ${ }^{1}$ Via clival canal, the communication between the inferior petrosal sinuses of both sides occurs. This canal is a natural way to neutralize the pressure on both internal jugular veins. $^{2}$

In the present study, we presented clival canal and foramen by multidetector computed tomography and three-dimensional images. It was obvious that, in 3-D images, clival canal and clival foramen were shown more clearly compared with the MDCT. In our 186 patients, evaluation of MDCT showed that clival foramen was absent in $66.7 \%(n=124)$ of patients. Only 33.3\% $(n=62)$ of patients had a clival foramen.

Tubbs et $\mathrm{l}^{8}$ investigated clival canals of the occipital portion of the clivus. One hundred dry skulls ( 80 adult and 20 children) and 47 adult cadavers were included, and the superior and inferior surfaces of their clivus were inspected for bony defects/canals. A canal of the clivus was identified in $5 \%$ of dry specimens and in $6.4 \%$ of cadaveric specimens. One diagonal and 5 more or less vertical canals were found. One canal was observed to have a single opening and 1 canal was found to have 3 openings. For the cadaveric canals, histology of the contents revealed no pituitary or notochordal tissue with only vascular anatomy consistent with veins. These venous structures appeared to connect parts of the basilar venous plexus. ${ }^{8}$ In the present study, the presence ratio of clival foramen was higher than that in the Tubbs et al's study. ${ }^{8}$ In the present study, with the help of advanced technology, MDCT, and 3-D images, we were able to detect clival canal and foramen in our patients.

Jalsovec and Winter ${ }^{1}$ described a vertically oriented canal in the posterior third of the clivus with openings located 7 and $2 \mathrm{~mm}$ above the anterior margin of the foramen magnum in the midline. Nayak et $\mathrm{al}^{2}$ reported a horizontally oriented canal in the middle third of the clivus that was located $18 \mathrm{~mm}$ in front of the anterior border of the foramen magnum and had a length of $6 \mathrm{~mm}$.

Clival canals of the occipital part of the clivus are incidental and represent osseous channels for intercommunication among parts of the basilar venous plexus or between this plexus and the diploic space of the clivus. ${ }^{9}$ Knowledge of the canal might be useful in patients of questionable clival fracture or during neurosurgical operations in this region. ${ }^{10}$ Before the surgical interventions in the clival region, the presence of the clival canal and foramen should also be known due to its vascular contents. By multidetector computed tomography and threedimensional images, clival canal and foramen may be viewed preoperatively.

\section{REFERENCES}

1. Jalsovec D, Vinter I. Clinical significance of a bony canal of the clivus. Eur Arch Otorhinolaryngol 1999;256:160-161

2. Nayak SR, Saralaya VV, Prabhu LV, et al. Clinical significance of a mysterious clival canal. Rom J Morphol Embryol 2007;48:427-429

3. Özçelik Ö, Çinar Ş, Sağiroğlu A, et al. Klival Kanalın Varyasyonları (variations of clival canal). Sağlik Bilimleri Dergisi (J Health Sci) 2012;21:195-199 
4. Bergman RA, Afifi AK, Miyauchi R. Illustrated Encyclopedia of Human Anatomic Variation. Opus V. Skeletal Systems: Cranium. Occipital bone. Available at: http://www.anatomyatlases.org/Anatomic Variants/SkeletalSystem/Text/OccipitalBone.shtml. Accessed 2007.

5. Goldman LW. Principles of CT and CT technology. J Nucl Med Technol 2007;35:115-128

6. Krmpotić-Nemanić J, Vinter I, Kelovizć Z, et al. Postnatal changes of the clivus. Ann Anat 2005;187:277-280

7. Collins P. Musculoskeletal system. In: Gray H, Bannister LH, Berry MM, Williams PL, eds. Gray's Anatomy: The Anatomical Basis of Medicine and Surgery. 38th ed. London, UK: Churchill Livingstone; 1995266

8. Tubbs RS, Griessenauer CJ, Loukas M, et al. The enigmatic clival canal: anatomy and clinical significance. Childs Nerv Syst 2010;26:1207-1210

9. Tubbs RS, Hansasuta A, Loukas M, et al. The basilar venous plexus. Clin Anat 2007;20:755-759

10. Joslyn JN, Mirvis SE, Markowitz B. Complex fractures of the clivus: diagnosis with CT and clinical outcome in 11 patients. Radiology 1988;166:817-821

\section{Transparotid Approach for the Treatment of Condylar Osteochondroma and Ankylosis of the Temporomandibular Joint}

\author{
Takaya Makiguchi, MD, PhD, Satoshi Yokoo, DMD, DMSC, \\ and Kensuke Kosugi, DDS, PhD
}

\begin{abstract}
Among the methods to treat temporomandibular joint (TMJ), preauricular, submandibular, retromandibular, and intraoral approaches have been described. These approaches, however, occasionally offer inadequate access, owing to the oblique course of the facial nerve, and access can be limited, especially to the medial and anterior part of the infratemporal fossa. The use of the transparotid approach can offer direct visualization of the facial nerves to prevent severe damage, and a wide work field can be achieved from the medial-anterior part of the infratemporal fossa to subcondylar region by retracting the mobilized facial nerves in either the superior or inferior direction.

The 2 patients reported herein illustrate the addition of a transparotid approach to the standard procedures for the removal of an osteochondroma and condylectomy with displaced bone fragment for ankyloses of TMJ from the infratemporal fossa.
\end{abstract}

Key Words: Ankylosis, osteochondroma, temporomandibular joint, transparotid approach

From the Department of Stomatology and Maxillofacial Surgery, Gunma University Graduate School of Medicine, Maebashi, Japan.

Received May 4, 2015.

Accepted for publication August 7, 2015.

Address correspondence and reprint requests to Takaya Makiguchi, Department of Stomatology and Maxillofacial Surgery, Gunma University Graduate School of Medicine, 3-39-22, Showa-machi, Maebashi,

Gunma 371-8511, Japan; E-mail: takayamakiguchi@gmail.com

The authors report no conflicts of interest.

Copyright 12015 by Mutaz B. Habal, MD

ISSN: 1049-2275

DOI: $10.1097 /$ SCS.0000000000002130
$\mathrm{T}$ umors originating from the condylar head and bone fragments caused by mandible condylar fractures can occasionally extend and become displaced in the medial-anterior direction into the infratemporal fossa. Among the methods available to treat temporomandibular joints (TMJ), preauricular, submandibular, retromandibular, and intraoral approaches have been described. ${ }^{1,2}$ Standard approaches to treat TMJ occasionally, however, do not offer adequate access for removal of the tumor and bone fragment(s) from the infratemporal fossa. Owing to the oblique course of the facial nerve, access is limited, particularly to the medial and anterior part of the infratemporal fossa.

The transparotid approach offers direct visualization of the facial nerves, and direct access above the condylar lesion via the parotid glands. $^{3-5}$ This approach is useful for the treatment of condylar head lesions extending medial and anterior into the infratemporal fossa. There have been some reports of the usefulness of this approach for the reduction and fixation of condylar fractures, but few regarding tumor resection and condylar ankyloses of TMJ. ${ }^{3}$

The 2 patients reported herein illustrate the addition of a transparotid approach for excision of a condylar osteochondroma and condylectomy for ankylosis of TMJ from the infratemporal fossa.

\section{SURGICAL PROCEDURE}

The preauricular incision, which was made along the crest of tragus, and submandibular incisions were combined in a "lazy-S incision." A skin flap was raised superficial to the parotid fascia superior up to the zygomatic arch. After superficial dissection, the parotid gland was dissected off the auricular cartilage, mastoid process and sternocleidomastoid muscle, taking care not to enter the parotid capsule.

Between the superior border of the posterior belly of digastric muscle and the apex of the cartilage of acoustic meatus, which was called the "pointer," the main trunk of facial nerve was firstly identified. The superficial part of parotid grand was elevated in the anterior direction and the facial nerve trunk and branches were dissected out. The exposed facial nerve branches were retracted in a superior or inferior direction according to the requisite surgical field. Before removal of the tumor or bone fragment, we proximally exposed the superficial temporal artery (STA) to identify the maxillary artery diverge from STA, and ligated it to avoid severe bleeding from damage of the vessel. This approach offered a wide work field under direct visualization from the medial and anterior part of the infratemporal fossa to the subcondylar region. Postoperatively, facial nerve paralysis temporally occurred, but could be improved completely with the administration of steroid and neuroactive agent for several months.

\section{CLINICAL REPORTS}

\section{Patient 1}

A 60-year-old man was referred to the Department of Oral and Maxillofacial Surgery, Gunma University Hospital, because of limited mouth opening, in 2009 with a 40 -year history of preauricular swelling and a 3-year history of rapidly limited mouth opening, and a sense of discomfort at the right preauricular region.

Examination showed an obvious mandible deviation $9 \mathrm{~mm}$ to the left and swelling of the right preauricular region (Fig. 1A). His mouth opening was $11 \mathrm{~mm}$, with the mandibular dental midline deviating $2 \mathrm{~mm}$ to the right (Fig. 1B).

A computed tomography (CT) scan showed swelling of the condylar head with significant medial and anterior extension (Fig. 1C-D). Elevated fluorine-18-fluorodeoxyglucose (FDG) positron emission tomography uptake was observed at the lesion (Fig. 1E). High FDG uptake occurs not only in malignant tumors, but also in 


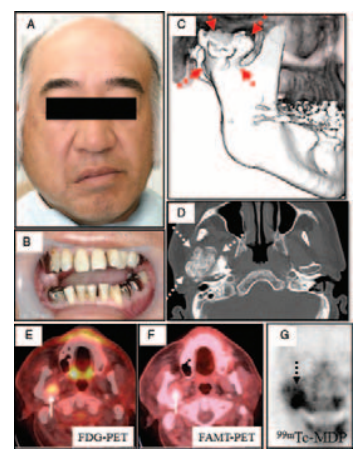

FIGURE 1. Patient 1. Preoperative view and images. A and B, Preoperative view. C and D, Preoperative computed tomography images. E, Fluorine-18fluorodeoxyglucose positron emission tomography. F, Fluoro- $\alpha$-methyltyrosine positron emission tomography. G, A bone scan scintigram carried out with ${ }^{99 \mathrm{~m}} \mathrm{Tc}-\mathrm{MDP}$

benign tumors and in inflammatory regions. Meanwhile, PET with L-3- $\left[{ }^{18} \mathrm{~F}\right]$ fluoro- $\alpha$-methyltyrosine (FAMT) shows high specificity for malignant tumors, based on uptake of FAMT into cancer cells via the L-type amino acid transporter 1 (LAT1). ${ }^{6}$ In this patient, high FAMT-PET uptake was not observed (Fig. 1F). Therefore, the clinical diagnosis of a benign tumor was made, not a malignant tumor, such as osteosarcoma. A bone scan scintigram, however, carried out with ${ }^{99 \mathrm{~m}} \mathrm{Tc}$-MDP revealed strongly increased uptake (Fig. 1G). Radical condylectomy for excision of the bony lesion was considered because of the high accumulation on bone scintigram, which indicated high activity of the tumor regardless of the diagnosis of benign lesion.

The excision was carried out with the transparotid approach because the tumor was extending in the medial and anterior direction into the infratemporal fossa and was difficult to be resected with a standard approach. A combination of preauricular and submandibular incisions, a "lazy-S incision" was used. Before removal of the tumor, we identified the maxillary artery diverging from STA, and ligated it. The buccal and zygomatic branches of the facial nerve were identified and retracted inferiorly and osteotomy of the clearly exposed subcondylar region was made inferior to the origin of the tumor (Fig. 2A). The lesion involving the condylar head was dissected from the surrounding tissues, that is, the temporal bone and the lateral pterygoid muscle, by retracting the piece laterally and the tumor mass was clearly resected (Fig. 2B). Histopathologic examination of the excised specimen revealed osteochondroma of the condyle.

Mild facial nerve paralysis occurred postoperatively, but it improved completely 3 months after the operation following administration of steroid and a neuroactive agent. Four years postoperatively, the patient presented with good facial symmetry (Fig. 2C). Mandibular function was good with a maximal incisal opening of

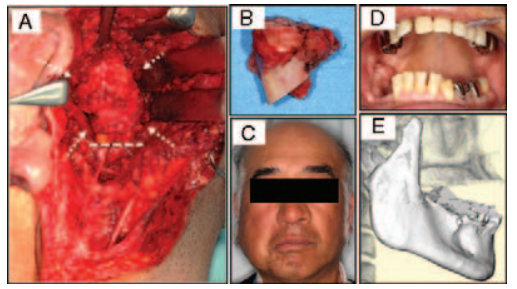

FIGURE 2. Patient 1. Intraoperative view, excised specimen and 4-year postoperative view. A, Intraoperative view. The tumor (white dash arrow) and subcondylar region, which would be osteotomized (white dash line), were clearly exposed. B, Excised specimen. C and D, Four-year postoperative view. $\mathrm{E}$, Four-year postoperative three-dimensional computed tomography.

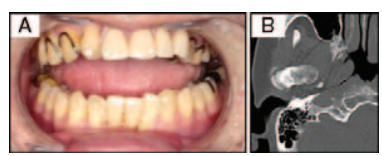

FIGURE 3. Patient 2. Preoperative view and images. A, Preoperative view. $\mathrm{B}$, Preoperative computed tomography image (axial view).

$35 \mathrm{~mm}$ with very mild deviation on opening on the right (Fig. 2D). There was no sign of recurrence on CT scan (Fig. 2E).

\section{Patient 2}

A 35-year-old man was referred because of limited mouth opening. He had been treated with a ventilator at an intensive-care unit at another hospital for over a month because of severe trauma involving multiple facial fractures in a traffic accident.

Clinically, mouth opening was restricted to $15 \mathrm{~mm}$ (Fig. 3A). Computed tomography scan confirmed the presence of a previous bilateral condylar head fracture. The right bone fragment deviated anteromedially and the condylar head was suspected to be a firm adhesion with severe scarring (Fig. 3B). The clinical diagnosis was ankylosis of the right TMJ because of the previous fracture. Condylectomy was considered using the transparotid approach because the bone fragment was displaced into the medial-anterior space and inferior into the infratemporal fossa and was difficult to release from the adhesion with the surrounding tissues or to remove by standard approaches. The main trunk of the facial nerve was exposed, following to the upper and lower division that divided from the main trunk. The buccal, zygomatic, and temporal branches, which arose from the temporofacial branches, were then dissected out. By retracting the mobilized zygomatic and buccal branch in the superior direction and the lower division in the inferior direction, the condylar neck was clearly exposed and osteotomy was performed, following removal of the condylar head with the displaced bone fragment (Fig. 4A-B).

An initial weakness of the facial nerve was observed, but it was resolved completely after 3 months. At the 6-month follow-up, the interincisal opening was $28 \mathrm{~mm}$ and there was good occlusal stability (Fig. 4C). Computed tomography scan showed precise excision of the condylar head with the displaced bone fragment (Fig. 4D).

\section{DISCUSSION}

Among many approaches to TMJ, while many extraoral and intraoral methods have been described, all have specific advantages

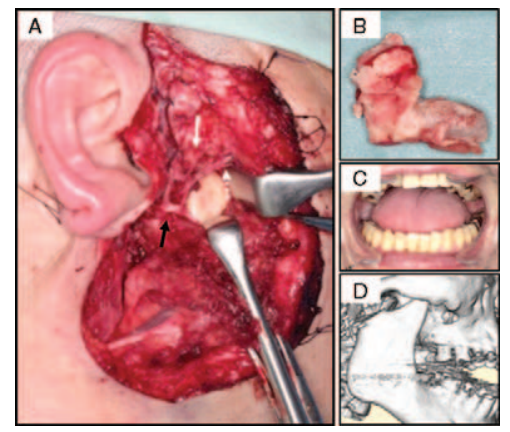

FIGURE 4. Patient 2. Intraoperative view, excised specimen and 6-month postoperative view. A and B, Intraoperative view and excised specimen. By retracting the mobilized zygomatic (white arrow) and buccal branch (white dash arrow) in the superior direction, and the lower division from the main trunk (black arrow) in the inferior direction, the condylar neck was clearly exposed and osteotomy was performed, following removal of condylar head with the displaced bone fragment. C, Six-month postoperative three-dimensional computed tomography image. D, The intrinsical opening was $28 \mathrm{~mm}$ at the 6-month follow-up. 
and disadvantages. ${ }^{1,2}$ The 2 patients reported herein illustrate the transparotid approach for osteochondroma removal and excision of a bone fragment with ankyloses of the TMJ via the infratemporal fossa. In patient 1 , the large tumor was extensive in the medial anterior direction into the infratemporal fossa. Radical condylectomy was considered, instead of conservative local resection, because high activity of the tumor was suggested by bone scintigram. In patient 2, the right bone fragment deviated in the medialanterior and inferior directions and the condylar head was suspected to have intensive adhesion with the surrounding tissues. In both patients, a wide work field was necessary from the medial-anterior part of the infratemporal fossa to the subcondylar region to ensure secure excision. Thus, we indicated the transparotid approach.

Condylectomy using a transzygomatic approach, ${ }^{7}$ in which the zygomatic arch was osteotomized to allow clear exposure of the subcondylar and infratemporal region, was considered one of the useful approaches. We, however, considered that the transparotid approach could be used to achieve a wide surgical field for these patients, for which zygomatic arch osteotomy traditionally might be needed.

The transparotid approach used herein offers several advantages regarding access to the medial-anterior region of the infratemporal fossa. The approach can offer direct visualization of the facial nerves and can prevent severe damage, and the wide work field offered by retracting in the superior or inferior direction mobilized the facial nerve branches. We can also decide the optimal location to transverse the parotid gland, to directly reach above the condylar lesion in the most direct manner, based upon the variety of sizes and locations.

One of the challenges of the transparotid approach is the potential for facial nerve disturbance. In all reported patients, nerve function returns to normal within 3 to 6 months. ${ }^{8}$ In our 2 patients, temporary weakness also occurred and recovered completely after 3 months. We, however, concluded that the administration of steroid and a neuroactive agent for several months was necessary after the transparotid approaches, to treat the acute facial nerve disturbances. Salivary fistula and Frey syndrome was not found in either of the patients reported herein.

In conclusion, the transparotid approach used here was found to offer a wide work field and was useful for the safe excision of the tumor and bone fragment extending to the medial-anterior region into the infratemporal fossa.

\section{ACKNOWLEDGMENT}

The authors thank Professor Toshirou Kondoh, at Department of Maxillofacial Surgery, Nihon University School of Dentistry at Matsudo, for his valuable cooperation in our study.

\section{REFERENCES}

1. Kreutiger KL. Surgery of the temporomandibular joint. Surgical anatomy and surgical incisions. Oral Surg Oral Med Oral Pathol 1984;58:637-646

2. Deng M, Long X, Cheng AH, et al. Modified trans-oral approach for mandibular condylectomy. Int J Oral Maxillofac Surg 2009;38:374-377

3. Leiggener C, Jaquiéry C, Kunz C, et al. Transparotid approach for tumor excision from the infratemporal space in temporomandibular joint reconstruction: a 3-year follow-up. Oral Surg Oral Med Oral Pathol Oral Radiol Endod 2010;109:e1-e4

4. Kanno T, Sukegawa S, Tatsumi H, et al. The retromandibular transparotid approach for reduction and rigid internal fixation using two locking miniplates in mandibular condylar neck fractures. Int J Oral Maxillofac Surg 2014;43:177-184

5. Kim BK, Kwon YD, Ohe JY, et al. Usefulness of the retromandibular transparotid approach for condylar neck and condylar base fractures. J Craniofac Surg 2012;23:712-715
6. Inoue T, Koyama K, Oriuchi N, et al. Detection of malignant tumors: whole-body PET with fluorine 18 alpha-methyl tyrosine versus FDGpreliminary study. Radiology 2001;220:54-62

7. Kumar VV. Large osteochondroma of the mandibular condyle treated by condylectomy using a transzygomatic approach. Int J Oral Maxillofac Surg 2010;39:188-191

8. Ellis E, McFadden D, Simon P, et al. Surgical complications with open treatment of mandibular condylar process fractures. J Oral Maxillofac Surg 2000;58:950-955

Ascertain the Safe Range From Foramen Rotundum to the Siphon of Internal Carotid Artery for Operation Through Pterygopalatine Fossa With Thin-Section Computed Tomographic Image

Jie Gao, MBBS, ${ }^{*}$ Tao Pan, MBBS, ${ }^{\dagger}$ Qianyan He, MBBS, ${ }^{*}$ Yuhao Zhao Jr, MMed, ${ }^{\ddagger}$ Li Li, MBBS, ${ }^{*}$ Mushui Qiu, MBBS, ${ }^{*}$ Hao Qu, MBBS, , Jingyi Shi, MBBS, ${ }^{*}$ Sirui Wang, MBBS, Kailiang Cheng Jr, MMed, ${ }^{\S}$ and Youqiong Li, MD*

Objective: This study aimed to ascertain the safe range from foramen rotundum to the siphon of internal carotid artery using three-dimensional reconstruction technique.

Methods: We scanned skulls of 121 volunteers to get the final results with thin-section computed tomographic image.

Results: The distance of AC was measured as $13.22(3.79) \mathrm{mm}$ (range, $8.33-105.67 \mathrm{~mm}$; 95\% CI [confidence interval], $8.55-$ $21.39 \mathrm{~mm}$ ). The angle to the sagittal plane was measured as 33.54 (9.23) $\mathrm{mm}$ (range, 5.38-66.58; 95\% CI, 30.88-34.20). The angle to the coronal plane was measured as 53.17 (10.48) $\mathrm{mm}$ (range, 5.60-75.02; 95\% CI, 51.29-55.06). The angle to the horizontal plane was measured as 9.43 (12.91) $\mathrm{mm}$ (range, -28.44 to 82.22 ; $95 \%$ CI, $7.11-11.76$ ).

Conclusions: These above-mentioned results can help locate these structures to help in minimizing surgical trauma to the nerves and blood vessels of the operation through pterygopalatine fossa under nasoendoscope.

From the *Department of the Anatomy, College of Basic Medicine, Jilin University, Changchun; †Xi'an Medical College, Xi’an; †First Affiliated Hospital of Jilin University; and §Third Affiliated Hospital of Jilin University, Changchun, China.

Received March 3, 2015.

Accepted for publication May 26, 2015.

Address correspondence and reprint requests to Youqiong Li, MD, Jilin University, Xinmin Street No. 126, 130021 Changchun, China;

E-mail: 297139732@qq.com

This work supported by College of Basic Medicine of Jilin University and the Third Affiliated Hospital of Jilin University.

Both JG and TP contributed equally to this work as the first authors.

The authors report no conflicts of interest.

Copyright $\odot 2015$ by Mutaz B. Habal, MD

ISSN: 1049-2275

DOI: $10.1097 /$ SCS.0000000000002002 
Key Words: Angle, foramen rotundum, pterygopalatine fossa $(\mathrm{PPF})$, the siphon of internal carotid artery

$P$ terygopalatine fossa (PPF) is a narrow space located between the posterior wall of the antrum and the pterygoid plates, and connected the cranial cavity with the foramen rotundum. ${ }^{1}$ The region has some important nerves, blood vessels, and it is near by the anterior cranial fossa, nasal, oral, eyes, cheeks, and other parts. Many lesions involve in this fossa. Because of its deep location and narrow space, lesions such as nasopharyngeal angiofibroma and nasopharyngeal carcinoma can spread through this natural channel. ${ }^{2}$

Operation through PPF under nasoendoscope is the most common method of operation in neurosurgery. The difficulty and danger of the operation through PPF under nasoendoscope is the fatal bleeding and complication of nerve system caused by the damage of the internal carotid artery. ${ }^{3}$ So knowing the iconic anatomical structure of the PPF and correlation distance well has an important significance.

Therefore, we measure the distance between foramen rotundum (point A) and the siphon of internal carotid artery (point B). Moreover, we also measure the angle of the line go through A and $\mathrm{B}$ to 3 plane (sagittal plane, coronal plane, and horizontal plane), which can assist surgeons to position precisely.

In this research, we chose thin-section computed tomographic images instead of surveying on corpses, which can find these above structures precisely and costs less compared with direct measurement using cadavers in previous researches.

\section{METHODS}

The whole head computed tomography scanning data of 121 patients were provided by Sino-Japanese Fellowship Hospital of Jilin University. Ages of the 121 selected samples are from 18 to 78. All the computed tomography images were obtained using the Siemens 64-row spiral CT in the Third Affiliated Hospital of Jilin University.

In the beginning, we adjust the images by making measured plane perpendicular to the line passing the edge of 2 bulbous oculi to eliminate the error formed by different body positions of people. We use three-dimensional reconstruction technique to make the reconstruction of the skull. Then, we ascertain the position of the siphon of internal carotid artery (point A) and foramen rotundum (point B), ${ }^{4,5}$ and record their layers (Fig. 1). In the meanwhile, we use three-dimensional reconstruction technique to build a coordinate system paralleled to the Frankfort horizontal plane and the nasal septum plane. The coordinate system takes point $\mathrm{A}$ as the coordi-

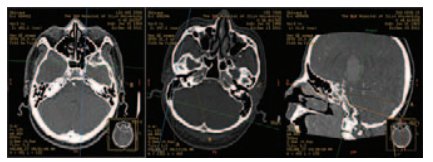

FIGURE 1. Ascertain the position of point $A$ and point $B$, then measure the vertical distance of these structures by building coordinate.

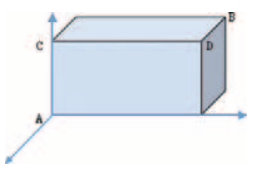

FIGURE 2. Use three-dimensional reconstruction technique to build a coordinate system paralleled to the Frankfort horizontal plane and the nasal septum plane (point $C$ is the projection of point $A$ in a plane parallel with Frankfort horizontal plane which includes point $B$, and point $D$ is the projection of point $C$ in the nasal septum plane which includes point $B$ ). nate origin (Fig. 2). Point $\mathrm{C}$ is the projection of point $\mathrm{A}$ in a plane parallel with Frankfort horizontal plane which includes point B, and point $\mathrm{D}$ is the projection of point $\mathrm{C}$ in the nasal septum plane which includes point $\mathrm{B}$. And later we measure the distance of $\mathrm{AC}$ and $\mathrm{BC}$. At last we calculate the distance between $\mathrm{A}$ and $\mathrm{B}$, and also measure the angle of the line go through A and B to 3 plane $^{6}$ (sagittal plane, coronal plane, and horizontal plane), which can make the position of the important structures more accurate.

All the statistics were entered into SPSS 19.0 for Windows for analysis. The measurements are presented as median (Q) for AC (because the data of $\mathrm{AC}$ do not conform to the normal distribution) and mean (SD) for the angle.

\section{RESULTS}

We get all the measures by three-dimensional measurement tools with three-dimensional reconstruction technique. The data measured in this study are shown in Table 1 and Table 2 . The data of $\mathrm{AC}$ do not conform to the normal distribution, so we use median and quartile as the statistics index. The distance of AC was measured as $13.22(3.79) \mathrm{mm}$ (range, $8.33-105.67 \mathrm{~mm}$; 95\% CI [confidence interval], $8.55-21.39 \mathrm{~mm})$. The angle to the sagittal plane was measured as $33.54(9.23) \mathrm{mm}$ (range, 5.38-66.58; 95\% CI, 30.8834.20). The angle to the coronal plane was measured as 53.17 (10.48) $\mathrm{mm}$ (range, 5.60-75.02; 95\% CI, 51.29-55.06). The angle to the horizontal plane was measured as $9.43(12.91) \mathrm{mm}$ (range, -28.44 to $82.22 ; 95 \% \mathrm{CI}, 7.11-11.76$ ).

\section{DISCUSSION}

Operation through PPF under nasoendoscope is the most common method of operation in neurosurgery. It is very dangerous when the internal carotid artery and nerve system is damaged and the following complication is severe. So, the key point to prevent complications is to be acquainted with the spatial structure of PPF and correlation distance.

We use three-dimensional reconstruction technique to make the reconstruction of the skull, and then we find out 2 points. ${ }^{7,8}$ The 1 is the siphon of internal carotid artery. It is a very important structure. It locates at the top of the lateral wall of sphenoid sinus, and the PPF is at the bottom. The siphon of the internal carotid artery is the lower bound of the artery. So, if surgeons want to operate through PPF under nasoendoscope without any damage, knowing the position of siphon of the internal carotid artery is necessary because the part which is beneath the siphon of internal carotid is all safe. ${ }^{9}$

The other one is foramen rotundum (point B), positioned at the outer side of the PPF and connected with the cranial cavity. It is a

\begin{tabular}{llll}
\hline TABLE 1. Measurement Results and $95 \% \mathrm{Cl}$ of $\mathrm{AC}(\mathrm{N}=112)$ & \\
\hline & Median (Q), mm & Range, $\mathrm{mm}$ & $95 \% \mathrm{CI}, \mathrm{mm}$ \\
$\mathrm{AC}$ & $13.22(3.79)$ & $8.33-105.67$ & $8.55-21.39$ \\
\hline
\end{tabular}

CI, confidence interval.

TABLE 2. Measurement Results and $95 \% \mathrm{Cl}$ of the Angle to the 3 Plane $(\mathrm{N}=112)$

\begin{tabular}{llll}
\hline & Mean (SD) & Range & 95\% CI \\
\hline The angle to the sagittal plane & $33.54(9.23)$ & $5.38-66.58$ & $30.88-34.20$ \\
The angle to the coronal plane & $53.17(10.48)$ & $5.60-75.02$ & $51.29-55.06$ \\
The angle to the horizontal plane & $9.43(12.91)$ & -28.44 to 82.22 & $7.11-11.76$ \\
\hline
\end{tabular}

CI, confidence interval; SD, standard deviation. 
very important structure in skull base. The optic nerve and siphon of the internal carotid artery are behind and above the foramen rotundum, so there is a safe range from foramen rotundum to the siphon of internal carotid artery. And the study is to ascertain the safe range and give guidance in surgeries.

We also measure the angle of the line go through point $\mathrm{A}$ and point $\mathrm{B}$ to 3 plane $^{10}$ (sagittal plane, coronal plane, and horizontal plane), which can make the position of the important structures more accurate.

Compared with the past studies, this study gives the quantized safety range of operation which will make the operation through PPF under nasoendoscope much more safer. Through the study, we can determine the scope of the operation more exactly and safely. So, as long as you do the operation through PPF under nasoendoscope according to the safe range the study gave, operations will be much more safer.

\section{REFERENCES}

1. Zheng HN, Wu Y, Lu YB, et al. Sectional and applied anatomy of pterygopalatine fossa for operative approach. Chinese J Clin Anat 2009;27:379-383

2. Zhang QX, Zou J, Qin G, et al. Operation path to pterygopalatine fossa under endoscope[J.]. China J Endoscopy 2007;13:795-797

3. Solari D, Magro F, Cappabianca P, et al. Anatomical study of the pterygopalatine fossa using an endoscopic endonasal approach: spatial relations and distances between surgical landmarks. J Neurosurg 2007;106:157-163

4. Bhatki AM, Carrau RL, Snyderman CH, et al. Endonasal surgery of the ventral skull base-endoscopic transcranial surgery. Oral Maxillofac Surg Clin North Am 2010;22:157-168

5. Hofstetter CP, Singh A, Anand VK, et al. The endoscopic, endonasal, transmaxillary transpterygoid approach to the pterygopalatine fossa, infratemporal fossa, petrous apex, and the Meckel cave. J Neurosurg 2010;113:967-974

6. Kishore S, Philippe M, Philippe P. Anatomical landmarks for transnasal endoscopic skull base surgery. Eur Arch Otorhinolaryngol 2012;69:171-178

7. Sun XJ, Pang RL, Zhao W, et al. The correlation study of the applied anatomy of internal carotid artery with brain DSA. Interv Radiol 2004;13:66-67

8. Satoru K, Hideaki M, Masashi S. Endoscopic endonasal transturbinate approach to the pterygopalatine fossa in the management of juvenile nasopharyngeal angiofibromas. Case Rep Otolaryngol 2012;2012:786262

9. Cavallo LM, Messina A, Gardner P, et al. Extended endoscopic endonasal approach to the pterygopalatine fossa: anatomical study and clinical considerations. Neurosurg Focus 2005;19:E5

10. Fortes ES, Sennes LU, Carrau RL, et al. Endoscopic anatomy of the pterygopalatine fossa and the transpterygoid approach: development of a surgical instruction model. Laryngoscope 2008;118:44-49

\section{Carotid Body Tumor: Clinical Features}

Irfan Kaygusuz, MD, ${ }^{*}$ Turgut Karlidag, MD, ${ }^{*}$ Erol Keles, MD, ${ }^{*}$ Sinasi Yalcin, $M D,{ }^{*}$ and Koray Yüksel, $M D^{\dagger}$

Abstract: Although carotid body tumor (CBT) is a rare neoplasm, it should always be considered in differential diagnosis of lateral neck masses. We shared the 10 years of CBT experience in our clinic and started a discussion on CBT with literature support. A total of 21 patients with CBT diagnosis in Frat University Hospital, Otorhinolaryngology Clinic, participated in the study. Patients were evaluated based on demographical data and particularities of the tumor. Participant patients were 19 women and 2 men, and their ages were between 21 and 79 (mean age $54.06 \pm 12.48$ ). The most frequent reason for the patients to apply to the hospital was painless swelling in the neck (76.2\%). Tumor was located in the right side of the neck in 10 patients $(47.6 \%)$, and in the left side of the neck in 11 (52.4\%). Twenty patients $(95.2 \%)$ had undergone computerized tomography angiography. Surgical treatment was applied to 19 patients $(90.5 \%)$ and the tumor was totally excised. According to Shamblin classification, 15 of the tumors of these patients were class II $(78.9 \%)$ and 4 were class III $(21.1 \%)$. In 1 patient $(5.3 \%)$, postoperative contusion infection that recovered after medical treatment was observed; in 2 patients $(10.5 \%)$, n. vagus injury was observed because of tumor's pervasion of $n$. vagus; and in 1 of these patients vocal cord paralysis was developed and this patient was later taken into thyroplasty surgery. Two patients $(10.5 \%)$ suffered $n$. hypoglossus injury, 1 of these recovered within 3 months postoperative and the other developed $n$. hypoglossus palsy. The size and extension of the tumor should be determined by preoperative imaging for the correct planning of surgical procedure. It should be taken into consideration that despite advanced surgical techniques, the rate of postoperative cranial nerve damage is still high.

Key Words: Carotid body tumor, chemodectoma, lateral neck mass

arotid body, localized in carotid artery bifurcation, is an autonomous organ specialized in regulating respiration and cardiovascular system and adjusting blood temperature. Carotid body tumor (CBT) is a common paraganglioma seen in head and neck region, developing from neural crest by replication of chemoreceptors in the neck during embryogenesis. ${ }^{1,2}$ The tumor is also called glomus tumor, chemodectoma, and nonchromaffin tumor. ${ }^{3}$ Carotid body tumor is usually very rare. $0.6 \%$ of head-neck tumors and $0.03 \%$ of all body tumors is CBT, and it is $60 \%$ to $70 \%$ of all paragangliomas and observed bilaterally in $5 \%$ to $10 \%$ of the patients. ${ }^{2,3}$ Although this tumor is rare, it should always be considered in differential diagnosis of neck masses localized laterally. ${ }^{2}$

Mostly the diagnosis of this tumor is delayed because of the lack of clinical symptoms and its slow growth pattern. This article aims to evaluate the files of 21 patients diagnosed with CBT during the last 10 years in our clinic retrospectively and to open a new discussion on those files supported by the literature.

\section{METHODS}

A total of 21 patients diagnosed with CBT in Frrat University Hospital, Otorhinolaryngology Clinic, between 2005 and 2014 formed the study group. Patient files were examined retrospectively.

From the $*$ Department of Ear, Nose and Throat Diseases, Faculty of Medicine, Firat University, Elazig; and †Department of Otorhinolaryngology, Government Hospital, Bingöl, Turkey.

Received March 7, 2015.

Accepted for publication May 26, 2015.

Address correspondence and reprint requests to Irfan Kaygusuz, MD, Professor of Otorhinolaryngology, Firat University Medical Faculty, Department of Otorhinolaryngology, 23200 Elazig, Turkey;

E-mail: kaygusuz_67@yahoo.com

The authors report no conflicts of interest.

Copyright $(2015$ by Mutaz B. Habal, MD

ISSN: $1049-2275$

DOI: $10.1097 /$ SCS.0000000000002003 


\begin{tabular}{lr}
\hline TABLE 1. Demographical Data of Patients and Tumor Specifications & \\
\hline Gender & 2 \\
Men & 19 \\
Women & \\
Age (between 21 and 79, mean $54.06 \pm 12.48)$ & 16 \\
Patients complaints & 6 \\
Swelling neck & 2 \\
Headache & 1 \\
Syncope & 1 \\
Swelling neck and syncope & 1 \\
Headache and vertigo & 1 \\
Headache and syncope & \\
Swelling neck and headache & \\
Dimension (on average) & \\
$35.80 \pm 13.34 \times 25.50 \pm 6.00 \mathrm{~mm}$ & \\
\hline
\end{tabular}

Patients were scrutinized with regard to demographical data, family history, their complaints, localization part of the tumor, preoperational radiological size of the tumor, preoperational hemoglobin and hematocrit levels, existence of preoperational angiography and embolization, classification of the tumor, treatment protocols implemented, inpatient period, postoperational complications, and follow-up duration (Tables 1 and 2).

Tumor was classified using Shamblin classification. ${ }^{4}$ Accordingly, small tumor that could easily be dissected from surrounding veins was determined as class I; tumor framing the veins partially was classified as class II; tumors affined with the carotid with its large mass and those required vascular reconstruction after dissection and framing carotid branches tightly were classified as class III. ${ }^{4}$

\section{RESULTS}

Out of the subject patients in the study 19 were women and 2 were men, and their ages differed between 21 and 79 (mean $54.06 \pm 12.48)$. Four of the patients applied to the hospital in $2005(19 \%), 1$ in $2007(4.8 \%), 1$ in $2010(4.8 \%), 5$ in 2012 (23.8\%), 6 in $2013(28.6 \%)$, and 4 applied in 2014 (19\%). None of the patients had CBT family history anamnesis. The most common reason to apply at the hospital $(76.2 \%)$ was painless swelling in the neck. It was followed by headaches $(23.8 \%)$ and syncope $(9.5 \%)$. Among patients who seek medical advice because of headaches, CBT was incidentally discovered in computerized scan in 5 patients $(23.8 \%)$. Tumor was localized in the left side of the neck in 10 patients $(47.6 \%)$, and was localized in the right side of the neck in 11 patients $(52.4 \%)$. Preoperational radiological dimensions of the tumor were $35.80 \pm 13.34 \times 25.50 \pm 6.00 \mathrm{~mm}$ on average. Preoperational hemoglobin values of the patients were $11.99 \pm 0.94(11.1-14.5) \mathrm{gr} / \mathrm{dL}$ on average and hematocrit values were found as $41.65 \pm 3.76(36.6-51.6)$ on average. One of the

TABLE 2. Procedures Applied to Patients and Resulting Complications

\begin{tabular}{lcllll}
\hline CT-A & PTE & CE & SC & Treatment & \multicolumn{1}{c}{ CO } \\
\hline 20 & 15 & CAR (1) & II (15) & Surgical (19) & Wound infection (1) \\
& & CVH (1) & III (4) & Non (2) & Pneumothorax (1) \\
& & & & & N. vagus damage (2) \\
& & & & & N. hypoglossus damage (2) \\
& & & & & Carotid artery rupture (1)
\end{tabular}

$\mathrm{CAR}=$ carotid $\quad$ artery $\quad$ rupture; $\mathrm{CE}=$ complications $\quad$ of embolization; $\mathrm{CO}=$ complications $\quad$ of operation; $\mathrm{CT}-\mathrm{A}=$ computed tomography-angiography; $\mathrm{CVH}=$ cerebrovascular hemorrhage; $\mathrm{PTE}=$ preoperative tumor embolization; $\mathrm{SC}=$ Shamblin's classification.

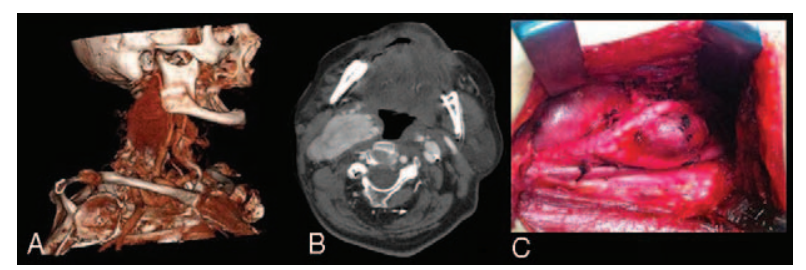

FIGURE 1. A, CT angiography; B, CT image of carotid body tumor; and C, perioperative image of carotid body tumor.

patients rejected computerized tomography angiography (CT-A), and the rest of the patients $(95.2 \%)$ took CT-A procedure to identify the vein feeding the tumor. In all the patients who undergone CT-A, it has been identified that the tumor was fed by the ascending pharyngeal artery (Fig. 1A and B). Of the patients, $71.4 \%(15 / 21)$ were administered preoperational embolization using ethanol or polyvinyl alcohol. During preoperational embolization, cerebrovascular hemorrhage was developed in 1 patient, and carotid artery rupture was developed in another as complications. Operations for these were cancelled and they were excluded from Shamblin classification. Nineteen of the patients $(90.5 \%)$ were treated with surgery and the tumors were excised totally (Fig. 1C). Fifteen of the operated tumors $(78.9 \%)$ were class II and $4(21.1 \%)$ were class III according to the Shamblin classification. In 1 patient, intensive care treatment became necessary postoperative, and as a result of intensive care intervention the patient developed pneumothorax and the patient was lost. In postoperative period, 1 patient $(5.3 \%)$ developed wound infection, which recovered after medical treatment; 2 patients (10.5\%) incurred cranial nerve damage because of the pervasion of the $n$. vagus by the tumor; and 1 of these developed vocal cord paralysis and undergone thyroplasty operation later. In 2 patients $(10.5 \%)$, n. hypoglossus damage occurred, 1 of these recovered in postoperative third month and the other developed n. hypoglossus paralysis. One patient $(5.3 \%)$ developed carotid bifurcation rupture during surgery and repaired with primary artery suturation by the cardiovascular surgeons. This patient did not develop postoperative neurological deficit. The specimens of all patients were reported as benign pathologically. Furthermore, lymph nodes dissected from the periphery of the tumor were reported as reactive lymph nodes. Thus, none of the patients were administered postoperative radiotherapy. Average inpatient period for the patients were $6.42 \pm 2.13$ days (3-11), and postoperative follow-up period were $37.13 \pm 39.99$ months $(2-99)$ on average. None of the patients relapsed during the follow-up period.

\section{DISCUSSION}

Paragangliomas are neoplasms originating from neural crest cells. This tumor is related to parasympathetic nervous system and neighboring arterial and cranial nerves. Paragangliomas are named based on their original locations. They are found usually in carotid bifurcation and are called CBTs. However, there are also jugular, vagal, nasal, orbital, laryngeal, and tympanic paragangliomas localized in the head-neck region. Carotid body tumors are the most common paraganglioma seen in the head-neck region. ${ }^{1,2}$

Although the etiology of CBT is uncertain, it could be sporadic or familial. Sporadic patients are usually women and the frequency of these patients being bilateral could be as high as 30\%.,3,5 Van der Bogt et $\mathrm{al}^{5}$ reported that the tumor was bilateral in 52 of the 72 patients they treated $(73 \%)$ and in $76 \%$ of those the family story was positive. The family story was not positive in any of the patients of this study. In none, the tumor was localized bilaterally and $90.5 \%(19 / 21)$ of the patients were women in accordance with the literature. 
Carotid body tumors are usually encountered in level with the hyoid bone, in the sternocleidomastoid muscle anterior, slow growing, painless, rubber-like, with limited movement in vertical plan, and mobile in lateral plan (Fontaine symptom) masses. ${ }^{3}$ The patients commonly complain from headaches, dizziness; neurological complaints such as syncope and hemifacial paraesthesia; dysphonia, odynophagia, and hoarseness because of the proximity of the tumor to the X and XII cranial nerves; and fluctuant hypertension because of catecholamine increase, flushing of the face, obstructive sleep apnea, and palpitation. ${ }^{1-3,6}$ In this study, the most common complaint was painless swelling in the neck $(76.2 \%)$. That was followed by headaches $(23.8 \%)$ and syncope $(9.5 \%)$. Other symptoms were not usually encountered. Carotid body tumor could be seen in both sides of the neck. According to Luna-Ortiz et $\mathrm{al}^{2}$, CBT uptake is equal in both sides of the neck (53.6\% in the left side; $46.4 \%$ in the right side). Sajid et $\mathrm{al}^{7}$ stated that the tumor could be found more frequently in the right side of the neck (58\%) and it was bilateral in $18 \%$ of the patients. In the series of this study, the tumor was localized in the left side of the neck in $47.6 \%$ of the patients, and was localized in the right side of the neck in $52.4 \%$ of the patients and there were no bilateral patients.

Preoperative diagnosis in patients with CBT is significant in preventing major complication development during surgery. ${ }^{8} \mathrm{Com}-$ puterized tomography and magnetic resonance imaging (MRI) are noninvasive and effective imaging systems for CBT diagnosis. In the diagnosis of paragangliomas, angiography is the most useful diagnostic test. Angiography provides information on the relation of the tumor with vascular structures, its size, localization, and on the veins that feed the tumor and the feasibility of an embolization. ${ }^{1,3}$ In this study, preoperative angiography was implemented in all patients except one patient who rejected CT-A. In all patients that undergone angiography, it has been determined that the tumor was fed by ascendant pharyngeal artery.

Cervical lymphadenopathy, bronchial scissure cist, lymph node metastases, salivary gland tumors, and carotid aneurism should be considered in differential diagnosis of CBTs. ${ }^{2}$ In our series, the patients were assessed the same way as well and preoperative differential diagnoses were performed.

The malignity rate of the CBTs was reported between $2 \%$ and $50 \%$. ${ }^{1,3}$ Today, there is no defined malignity criteria based on the tumor's histological characteristics or the degree of its vascular invasion, but the metastasis to peripheral lymph nodes or to distant organs is accepted as malignity criteria. ${ }^{2,9}$ On the basis of that criterion, it has been accepted that approximately $5 \%$ to $10 \%$ of all patients are in malign character. Although distant organ metastasis is rare, metastases to liver, bone, kidney, lungs, breast, pancreas, and thyroid gland were reported in the literature. ${ }^{1,2}$ On pathological results of the patients of this study, no malignity was reported. In 9 patients (47.4\%), the lymph nodes excised reported as reactive lymph nodes.

In CBT treatment, embolization, surgical resection, and radiotherapy could be administered. ${ }^{3,6,10}$ However, the fact that malignity potential is low for life expectancy and the relatively slow growth rate of the tumor, surgical procedures are not suggested for patients $>60$. Basic surgical principles for CBT excision are to provide a good view, to protect neurovascular structures by exposure, subadventitial tumor dissection, external artery ligation if necessary, and ventricular shunt with grafting. ${ }^{1,2}$ Surgical subadventitial resection of the tumor is considered as the optimum approach to excise these tumors today. ${ }^{2}$ Using this method, dissection will be possible through the avascular area between the tumor and carotid system. During the excision of the tumor it is suggested that it should be freed from the lateral face of the artery initially, and then the medial face should be dissected and later should proceed toward the bifurcation. ${ }^{8}$ Surgical resection was practiced on $90.5 \%$ of the patients in this study. Six patients $>60$ years were informed about the condition and the risks of the surgery that would be applied; after their approval 4 of them were operated and they showed no postoperative complications. However, in the 2 remaining patients a complication developed after preoperative embolization (minimal dissection in carotid bifurcation and cerebrovascular hemorrhage) and their operations were cancelled.

It has been reported that early CBT was radio resistant. ${ }^{11}$ However, certain studies reported positive response to radiotherapy. ${ }^{12,13}$ Luna-Ortiz et al $^{2}$ suggested radiotherapy in unresectable sized tumors, high-risk patients, patients with metastatic lesions, and in patients where a full resection is not possible. The tumors of all the patients in this study were removed totally using surgical excision, and none were administered radiotherapy.

Today, preoperative embolization is topical. It has been argued that it reduces the blood loss and facilitates the surgical dissection. ${ }^{14}$ Even though certain studies reported that blood loss decreased and surgical period shortened in patients who were administered embolization, that fact was not confirmed by other studies. These determined that there was no difference in blood loss volume, operation time, or in perioperative morbidity. ${ }^{15}$ The risk of postembolization palsy is around $10 \% .{ }^{15}$ Luna-Ortiz et $\mathrm{al}^{2}$ did not apply embolization to any of their 66 patients diagnosed with CBT. However, 3 of the 46 patients intervened surgically needed vascular reconstruction. Makeieff et $\mathrm{al}^{8}$ also reported that they have not applied embolization to none of their 52 patients that they operated on. All our patients have received embolization 1 day before their operations. One patient developed minimal dissection in carotid bifurcation during embolization, another started to speak nonsense in 14th postembolization hour, applied an emergency diffusion MRI, diagnosed with cerebrovascular hemorrhage, and was transferred to neurological clinic. The authors think that preoperative embolization helps decrease hemorrhage considerably.

The size of the tumor increases the risks of hemorrhage and cranial nerve damage during surgery. Tumors $>4$ to $5 \mathrm{~cm}$ usually have pervaded the carotid artery either completely or partially. ${ }^{1}$ In this study, parallel to the literature review, average tumor size was found to be $36.60 \pm 17.64 \times 35.16 \pm 10.08 \mathrm{~mm}$ in average, and 15 tumors $(78.9 \%)$ were determined to be class II, and $4(21.1 \%)$ were class III when classified according to the Shamblin classification. In some patients with Shamblin-III tumor, posttumor excretion reconstruction with synthetic grafts or autologous saphenous vein graft could be necessary. ${ }^{1}$ In the patient subject of this study with Shamblin class III (1/4), carotid artery damage has developed during surgery. Carotid artery bifurcation integrity was damaged in that patient and arterial reconstruction with primary suturation became necessary.

It has been determined that the development rate of postoperative cranial nerve paralysis was $32 \%$ to $44 \%$ and the rate for other neurological complications was $8 \%$ to $20 \%$. It has also been reported that the most frequently affected cranial nerve as a result of neurological damage was the marginal mandibular branch of the 7 th cranial nerve, n. hypoglossus and $n$. vagus. ${ }^{1,2,6}$. The possibility of a postoperative neurological damage is higher in Shamblin class III patients. ${ }^{2}$ Makeieff et $\mathrm{al}^{8}$ reported $42.1 \%$ nerve damage ratio in 52 patients with CBT that they have operated on and also reported that 6 of these patients developed Horner syndrome and 4 developed permanent $n$. vagus paralysis as a result. Davidovic et $\mathrm{al}^{3}$ in their series of 12 patients have reported that 2 patients have developed hypoglossal nerve paralysis. In the series of this study, cranial nerve damage was observed in 4 patients $(21 \%), 2$ of which $(10.5 \%)$ developed permanent nerve paralysis. N. vagus was damaged in 2 of our patients, and in the other $2 \mathrm{n}$. hypoglossus damage was observed. One of the patients with $\mathrm{n}$. vagus damage developed 
vocal cord paralysis and later received thyroplasty surgery. The other patient with $n$. vagus damage recovered without further complications. One of the patients with $\mathrm{n}$. hypoglassus damage developed permanent paralysis, and the other recovered after postoperative third month. In this study, 2 of the patients that developed cranial nerve damage were Shamblin class III and 2 were Shamblin class II patients. This finding supports that the Shamblin II and III patients are more likely to develop cranial nerve damage than others.

Complications like temporary cerebral ischemia, mark infections, laryngotracheal edema requiring tracheotomy, and hematoma development leading to hypovolemia were reported after CBT surgery. ${ }^{2}$ In the patients of this study, mark infection was observed in 1 patient postoperative and recovered with medical treatment.

Literature review demonstrates that surgery mortality varies between $1 \%$ and $13 \%$. It has been accepted that the reason for this variance in mortality rates was because of the surgery techniques implemented by medical centers, the size of the tumor, and large age span of the patients, as well as the intrinsic characteristics of the tumor. ${ }^{2,7}$ In the series of this research, postoperative intensive care treatment was needed for 1 patient, the patient developed pneumothorax after the interventions in intensive care and the patient was lost on 20th postoperative day. Thus, the mortality rate for the study was determined as $4.8 \%$. Reoccurrence rate in CBT was reported to be $6 \%{ }^{3}$ In this study, no reoccurrence was reported among the patients after an average follow-up period of $37.13 \pm 39.99$ months (2-99).

\section{CONCLUSIONS}

The CBT is a rare neoplasm, it should be considered especially for differential diagnosis of lateral neck masses. After determining the size and prevalence of the tumor by preoperative imaging, the patient should be taken to surgery well prepared. It should be remembered that despite advanced surgery techniques, the prevalence of postoperative cranial nerve paralysis is still rather high. Therefore, the patient should be clearly informed about his disease and operational risks during preoperative period. Carotid body tumor excision, which demands high concentration and patience by the primary surgeon and his team, is satisfactory to obtain a cure. The possibility of a cure depends highly on the experience and the skills of the surgeon.

\section{REFERENCES}

1. Patlola $\mathrm{R}$, Ingraldi $\mathrm{A}$, Walker $\mathrm{C}$, et al. Carotid body tumor. Int J Cardiol 2010;143:7-10

2. Luna-Ortiz K, Rascon-Ortiz M, Villavicencio-Valencia V, et al. Carotid body tumors: review of a 20-year experience. Oral Oncol 2005;41:56-61

3. Davidovic LB, Djukic VB, Vasic DM, et al. Diagnosis ana treatment of carotid body paraganglioma. 21 years of experience at a clinical center of Serbia. World J Surg Oncol 2005;3:10

4. Shamblin WR, ReMine WH, Sheps SG, et al. Carotid body tumor (chemodectoma). Clinicopathologic analysis of ninety cases. Am J Surg 1971;122:732-739

5. Van der Bogt KE, Vrancken Peeters MP, van Baalen JM, et al. Resection of carotid body tumors: results of an evolving surgical technique. Ann Surg 2008;247:877-884

6. Qin RF, Shi LF, Liu Yp, et al. Diagnosis ana surgical treatment of carotid body tumors: 25 years experience in China. Int J Oral Maxillofac Surg 2009;38:713-718

7. Sajid MS, Hamilton G, Beker DM. A multicenter review of carotid body tumour management. Eur J Vasc Endovasc Surg 2007;34:127-130

8. Makeieff M, Raingerad I, Alric P, et al. Surgical management of carotid body tumors. Ann Surg Oncol 2008;15:2180-2186

9. Patetsios P, Gable Dr, Garrett WV, et al. Management of carotid body paragangliomas ana review of a 30-year experience. Ann Vasc Surg 2002;16:331-338
10. Ma D, Liu L, Yao $\mathrm{H}$, et al. A retrospective study in management of carotid body tumour. Br J Oral Maxillofac surg 2009;47:461-465

11. Elshaikh MA, Mahmoud-Ahmed AS, Kinney SE, et al. Recurrent headana-neck chemodectomas: a comparison of surgical and radiotherapeutic results. Int J Radiat Oncol Biol Phys 2002;52:953-956

12. Saldana MJ, Salen LE, Travezan R. High altitude hypoxemia and chemodectomas. Hum Pathol 1973;4:251-263

13. Vuorela AL, Jakobsson M, Anttinen J. Slowly growing pulmonary metastases of malignant cervical chemodectoma. Acta Oncol 1994;33:77-78

14. LaMuraglia GM, Fabian RL, Brewster DC, et al. The current surgical management of carotid body paragangliomas. $J$ Vasc Surg 1992; 15:1038-1045

15. Tikkakoski T, Luotonen J, Leinonen S, et al. Preoperative embolization in the management of neck paragangliomas. Laryngoscope 1997; 107:821-826

\section{Primary Nasal Reconstruction in Self-Inflicted Nasal Injury}

\author{
Abizer Kapadia, MCh, Jerry R. John, MCh, Sunil Gaba, MCh, \\ and Ramesh Kumar Sharma, MCh, DNB
}

Abstract: Self-inflicted injury of the nose is extremely rare. It may be associated with severe psychopathology and suicidal ideation. The authors report a case of a 24-year-old man, who presented with soft-tissue loss over both the alae of his nose. He had cut off the alar rims with an ordinary razor blade. He was overtly concerned about his nose being excessively broad and fat. A diagnosis of body dysmorphic disorder with nonsuicidal selfinjury was made. Patient was observed during 72 hours in hospital with psychiatric support and local dressings. The authors undertook primary nasal reconstruction with nasolabial flaps on both sides for coverage. In conclusion, self-inflicted nasal injury mandates a judicious balancing of psychiatric support and surgical reconstruction. This can prevent untoward sequelae including further self-harm and suicide.

Key Words: Body dysmorphic disorder, flap, nose, reconstruction, self-harm, trauma

$\mathrm{T}$ he nose is an asset and considered a matter of great pride and dignity. Mutilation of the nose was a punishment meted out to adulterers and thieves. Reconstructive surgery for nasal injuries is described as early as 600 BC. Deliberate self-harm and mutilation of the nose, however, is extremely uncommon and underreported. Self-mutilative behavior is defined as the deliberate destruction of body tissue without conscious suicidal intent. ${ }^{1}$ These injuries may be associated with severe psychopathology and suicidal ideation.

From the Department of Plastic Surgery, Post Graduate Institute of Medical Education and Research, Chandigarh, India.

Received March 28, 2015.

Accepted for publication June 28, 2015.

Address correspondence and reprint requests to Abizer Kapadia, MCh, Department of Plastic Surgery, Post Graduate Institute of Medical

Education and Research, Chandigarh, India;

E-mail: abizer.kapadia@gmail.com

The authors report no conflicts of interest.

Copyright $\odot 2015$ by Mutaz B. Habal, MD

ISSN: 1049-2275

DOI: $10.1097 /$ SCS.0000000000002043 
Such wounds may range from superficial lacerations to complete autoamputation of the part.

\section{CLINICAL REPORT}

A 24-year-old man presented 24 hours after incising both the alae of his nose with an ordinary razor blade, looking at himself in a mirror. He subsequently placed a handkerchief over his nose to aid in stop bleeding and informed his father about the incident, who brought him to the hospital emergency department. The patient was a high school dropout and working as a salesman at a cloth shop.

His history included depression; however, there were no prior attempts of self-harm. He reported stress in his life and constantly being teased and ridiculed by his peers of his nose being too fat and broad. He had taken prior consultations, on a number of occasions with local physicians, who had advised reassurance. He was concerned about his nose being excessively broad and fat, and accordingly being the main reason of not being in a relationship or having a better job. Psychiatric assessment did not elicit evidence of psychosis or suicidal intent but revealed moderate clinical depression. A diagnosis of body dysmorphic disorder (BDD) with nonsuicidal self-injury (NSSI) was subsequently made.

Clinical examination revealed near-symmetrical lacerations and excision of both alae, which were skin and soft-tissue deep, exposing the lateral crus of lower lateral cartilages on both sides (Fig. 1 top row left). The nasal cartilage framework and lining were intact. Injury was corroborated as clean-cut with a sharp blade as informed by the patient. There was no previous scarring or evidence of previous injury to the nose or any other body parts. Intranasal examination revealed no abnormality.

Given the history, psychiatric counseling and antidepressants (tablet escitalopram $10 \mathrm{mg}$ once a day and zolpidem $6.25 \mathrm{mg}$ as needed) were started. Preliminary aid in the form of cleansing and dressing with Vaseline gauze was done at the time of admission. Following 72 hours of observation, and his general well-being stable throughout, patient was taken up for surgery under general anesthesia. Debridement and peninsular nasolabial flaps were performed for coverage of the exposed cartilages, on both sides (Fig. 1 top row right). Postoperative course was uneventful. The patient was discharged after 3 days of observation and counseling and advised to continue tablet escitalopram (SSRI class of antidepressant). He was followed-up regularly and after 3 weeks detachment and inset of the flap was done. Subsequently, patient underwent one sitting of flap thinning 4 months later. This was performed as an office procedure under local anesthesia and it improved the alar contour. The patient has been on follow-up for more than a year and is very satisfied with his final result. We obtained a score of 62 of 100 on subjecting the patient to the FACE-Q satisfaction scale specific to the nose. ${ }^{2}$ The overall facial appearance satisfaction level on the FACE-Q scale was 64. He requested no further procedures or rhinoplasty (Fig. 1 bottom row). The patient was advised tablet escitalopram $10 \mathrm{mg}$ for a period of 6 months and then was stopped.

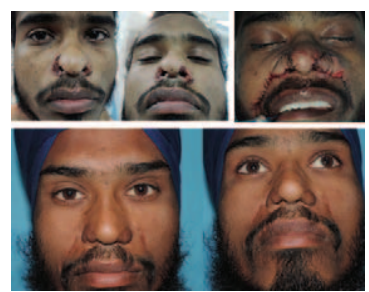

FIGURE 1. Top row left-Preoperative picture shows bilateral alar loss following self-inflicted cut injury with razor blade. Top row right-Primary alar reconstruction with bilateral nasolabial flaps. Bottom row-Picture, 1-year postoperative, shows well-settled flaps with satisfactory alar contour.

\section{DISCUSSION}

Nonsuicidal self-injury is a newly proposed diagnostic category in the Diagnostic and Statistical Manual of Mental Disorders, Fifth Edition. ${ }^{3}$ Several reports exist on self-mutilation with or without the background of BDD. ${ }^{1,4}$ Suicide and suicide attempts were reported in up to $10 \%$ of self-harm patients. Facial self-mutilation, particularly of the nose, however, is exceedingly rare. We performed a literature search on MEDLINE covering articles from 1990 to 2015 with the term, "self-inflicted injury AND nose." Only one similar case report was found. ${ }^{5} \mathrm{We}$, however, did not come across any patient of self-inflicted injury of nose with BDD. This fact highlights the rarity of the situation.

Body dysmorphic disorder, on the contrary, is the current name for the disease previously called dysmorphophobia. It is characterized by excessive preoccupation with nonexistent or minimal defects in one's appearance that cause marked distress and life disruption. ${ }^{6}$ The most common affected body areas are the nose, hair, and genitalia. Approximately, $72 \%$ of BDD patients seek surgery, $48 \%$ of such patients have considered suicide, and $27 \%$ have a suicide plan. ${ }^{7}$ Selfharm is typically linked with depression, schizophrenia, and substance abuse. Our patient experienced anxiety, preoccupation, and markedly excessive concern causing clinically significant distress. He had features of chronic depression without features of psychosis. We did not find any evidence of substance abuse.

Treatment in such sensitive patients incorporates multidisciplinary care. Counseling and concomitant psychiatric treatment, including antidepressant drugs, forms the basis of initial management. Surgical management aims to reestablish normal anatomy and preserve as much function as possible. Elaborate and many-staged reconstruction is often not preferred; however, it is imperative to provide an acceptable degree of cosmesis too. Body dysmorphic disorder is underdetected in patients presenting for cosmetic surgery, and patients with an established diagnosis of BDD, do not currently appear to be good surgical candidates, even with concomitant psychiatric treatment. ${ }^{8}$ Proactive management, however, is warranted in patients of self-inflicted injury.

In conclusion, BDD with self-mutilation is a growing concern for the reconstructive surgeon and mandates a judicious balancing of psychiatric support and surgical reconstruction. This can prevent untoward sequelae including further self-harm and suicide.

\section{REFERENCES}

1. Chan JK, Jones SM, Heywood AJ. Body dysmorphia, self-mutilation and the reconstructive surgeon. J Plast Reconstr Aesthet Surg 2011;64: 4-8

2. Pusic AL, Klassen AF, Scott AM, et al. Development and psychometric evaluation of the FACE-Q satisfaction with appearance scale: a new patient reported outcome instrument for facial aesthetics patients. Clin Plast Surg 2013;40:249-260

3. American Psychiatric Association. Diagnostic and Statistical Manual of Mental Disorders. 5th ed. Washington, DC: America Psychiatric Publishing; 2013

4. Morioka D, Ohkubo F, Amikura Y. Self-mutilation by a patient with borderline personality disorder. Aesthetic Plast Surg 2014;38:812-814

5. Ghaffari-Nejad A, Kerdegari M, Reihani-Kermani H. Self-mutilation of the nose in a schizophrenic patient with Cotard syndrome. Arch Iran Med 2007;10:540-542

6. Phillips KA. The Broken Mirror: Understanding and Treating Body Dysmorphic Disorder NY: Oxford University Press; 2005

7. Phillips KA, Coles ME, Menard W, et al. Suicidal ideation and suicide attempts in body dysmorphic disorder. J Clin Psychiatry 2005;66:717725

8. Dey JK, Ishii M, Phillis M, et al. Body dysmorphic disorder in a facial plastic and reconstructive surgery clinic: measuring prevalence, assessing comorbidities, and validating a feasible screening instrument. JAMA Facial Plast Surg 2015;17:137-143 